US Army Corps of Engineers ${ }_{\circledast}$

Engineer Research and

Development Center

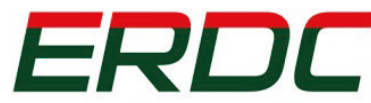

INNOVATIVE SOLUTIONS for a safer, better world

Flood and Coastal Systems R\&D Program

Coastal Ocean Data Systems Program

\title{
Unmanned Aircraft Systems to Support Environmental Applications within USACE Civil Works
}

Glenn M. Suir, Molly Reif, Shea Hammond, Sam Jackson, June 2018 and Katherine Brodie

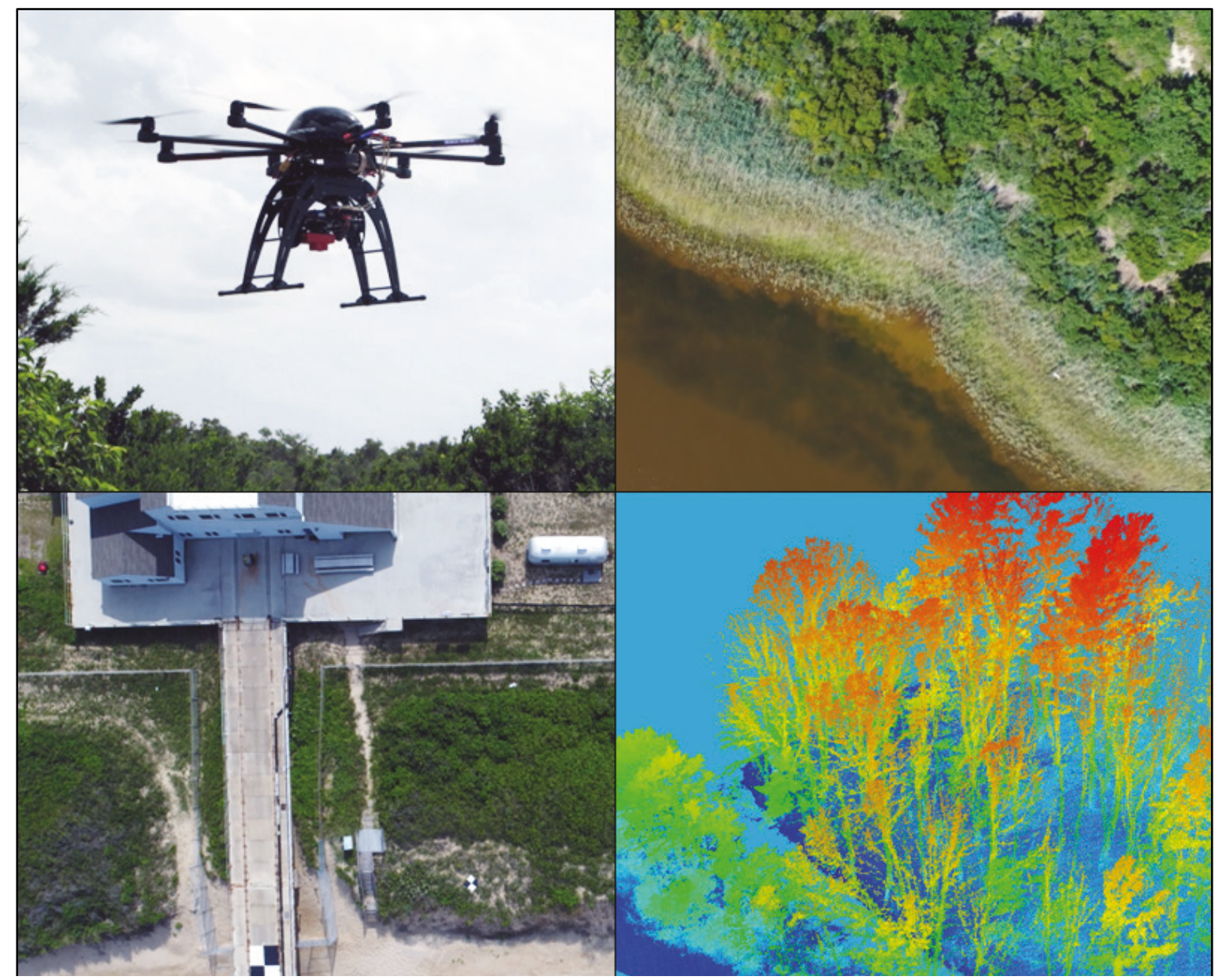


The U.S. Army Engineer Research and Development Center (ERDC) solves the nation's toughest engineering and environmental challenges. ERDC develops innovative solutions in civil and military engineering, geospatial sciences, water resources, and environmental sciences for the Army, the Department of Defense, civilian agencies, and our nation's public good. Find out more at www.erdc.usace.army.mil.

To search for other technical reports published by ERDC, visit the ERDC online library at http://acwc.sdp.sirsi.net/client/default. 


\section{Unmanned Aircraft Systems to Support Environmental Applications within USACE Civil Works}

Glenn M. Suir

Environmental Laboratory

U.S. Army Engineer Research and Development Center Louisiana State University - Military Sciences Building Baton Rouge, LA 70803

Molly Reif

Environmental Laboratory

U.S. Army Engineer Research and Development Center Joint Airborne Lidar Bathymetry Technical Center of Expertise

Kiln, MS 39556

Shea Hammond and Sam Jackson

Environmental Laboratory

U.S. Army Engineer Research and Development Center

Vicksburg, MS 39180-6199

Katherine Brodie

Coastal and Hydraulics Laboratory

U.S. Army Engineer Research and Development Center

Duck, NC 27949

Final report

Approved for public release; distribution is unlimited.

Prepared for U.S. Army Corps of Engineers

Washington, DC 20314-1000

Under Project No. 468426, "Flood and Coastal Systems R\&D Program"

Project No. 468431, "Coastal Ocean Data Systems Program” 


\section{Abstract}

The combination of static infrastructure with dynamic and diverse landscapes creates management challenges for navigation, storm damage reduction, and ecosystem health that are exacerbated during natural disasters. To accomplish the U.S. Army Corps of Engineers (USACE) flood risk management (FRM) mission, accurate and updated identification of environmental, physical, and infrastructure features is required. The USACE has identified a number of Research and Development (R\&D) opportunities to help reduce disaster risks, including cost-efficient technology, such as Unmanned Aircraft System (UAS) technology for accurate, detailed, and timely two-dimensional and three-dimensional monitoring of coastal and riverine landscapes. To that end, the USACE Flood and Coastal Systems R\&D Program has initiated an effort focused on identifying and developing defendable and consistent UAS-based methodologies and data products to help address FRM goals. Specifically, this report focuses on identifying the role of UAS technology to support environmental missions and applications related to FRM. While it does not address operational classification, guidance, and policies, which have been established and published, the report does include a technical review with district feedback of USACE-related environmental needs, and it assesses the role of UAS-based data product research and development.

DISCLAIMER: The contents of this report are not to be used for advertising, publication, or promotional purposes. Citation of trade names does not constitute an official endorsement or approval of the use of such commercial products. All product names and trademarks cited are the property of their respective owners. The findings of this report are not to be construed as an official Department of the Army position unless so designated by other authorized documents. 


\section{Contents}

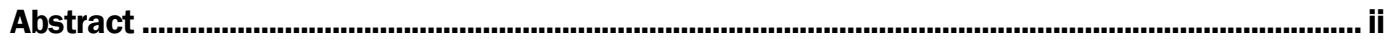
Figures and Tables......................................................................................................................iv

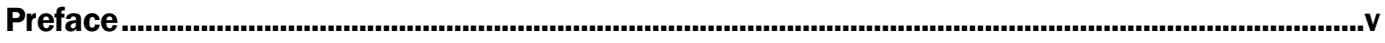
Unit Conversion Factors .................................................................................................................
Abbreviations ..........................................................................................................................................vii

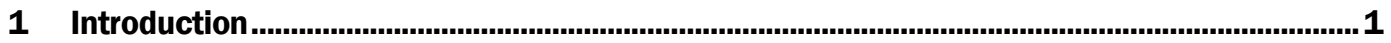
1.1 Background - Flood Risk Management (FRM) challenges ..................................... 1

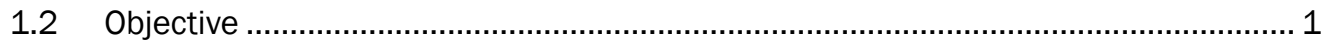

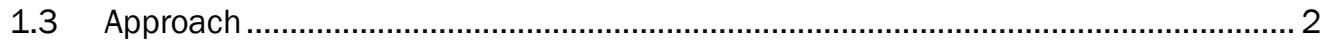

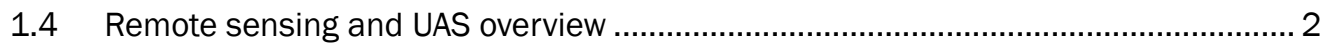

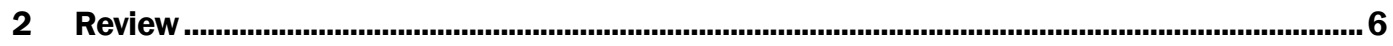

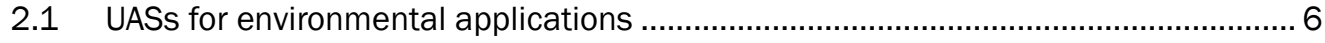

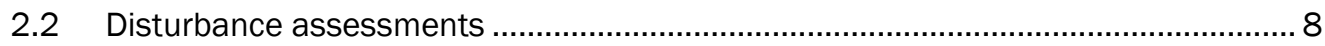

2.3 Riverine and coastal systems ....................................................................... 9

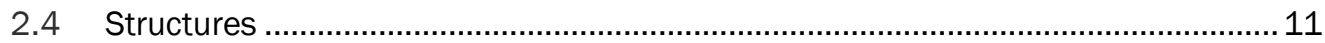

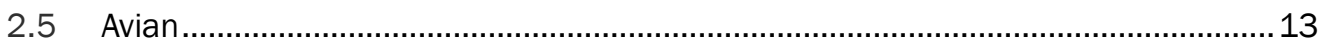

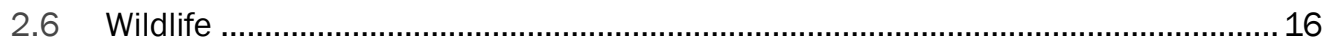

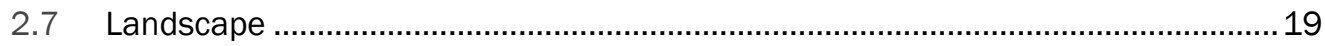

2.8 USACE considerations .................................................................................... 21

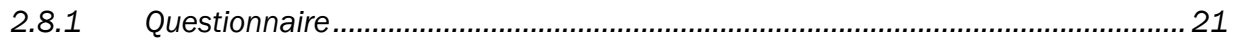

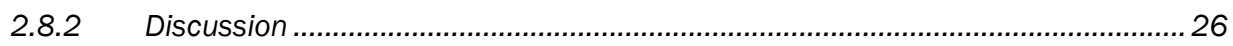

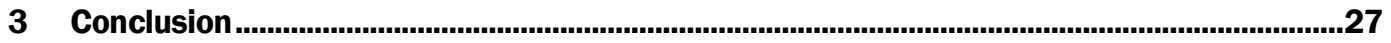

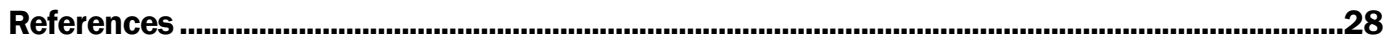

\section{Report Documentation Page}




\section{Figures and Tables}

\section{Figures}

Figure 1. Orthomosaic created from 785 images captured at $200 \mathrm{~m}$ with a ground resolution of $5.13 \mathrm{~cm}$ using RGB camera. (Courtesy of Ezequiel et al. [2014]).

Figure 2. Detrended pre- and post-flood DEMs and DEM differencing. Detrended elevations reflect the removal of valley slope and normalization relative to mean reach elevation; positive values are above mean elevation, negative values are below mean elevation. (Courtesy of Tamminga et al. [2015]).

Figure 3. Panel A shows the DTM (shaded presentation) of levees in the test area, and Panel B shows a comparison of profiles of the direct field survey (GNSS) and the DTM generated from the UAS. (Courtesy of Bakula et al. [2017])

Figure 4. Panel A shows the automatic software identification of a bird, Panel B shows the calculated canopy height from the 3D cloud, and Panel C shows the DSM for Langenwerder Island. (Courtesy of Grenzdörffer [2013]).

Figure 5. A thermal infrared spatial index map (A) and a representative individual thermal IR image (B) of the grey seal colony at Hay Island, NS, Canada. This footprint of the individual image is projected onto the spatial index, providing a detailed view of adult and YOY grey seals and the habitats surveyed (rock, beach and frozen ground). This map was created with ArcMap GIS software (version 10.4.1, ESRI Inc.). (Courtesy of Seymour et al. [2017])

Figure 6. (A) Thermal imagery with overlaid human-identified seal points (red=YOY, green=adult). (B) Red seal polygons outlined by blue convex hulls. (C) Tier 1 model classification of seals. Blue polygons are adult aggregations, orange polygons are YOY aggregations, green polygons are individual adults and red polygons are individual YOYs. (D) Aggregation polygons after high-pass filtering, broken up into individual adults and YOYs. (Courtesy of Seymour et al. [2017])

Figure 7. Methods for generating sample datasets: (A) represents the UAS orthophoto (RGB); (B) the multi-resolution segmentation; (C) the reference polygons dataset; and (D) the selected invasive plant species objects $(H$. mantegazzianum). (Courtesy of Michez et al. [2016])

\section{Tables}

Table 1. Overview of high-resolution (5 $\mathrm{m}$ or higher spatial resolution) satellite imagery sources available to the USACE... 


\section{Preface}

This study was prepared for the U.S. Army Corps of Engineers and was funded under the Coastal Ocean Data Systems (CODS) Program and Flood and Coastal Systems R\&D Program (FCS) under "Unmanned Aircraft System Support to Flood Risk Management." FCS is funded by the Flood Risk Management (FRM) business line of the Headquarters, U.S. Army Corps of Engineers (HQUSACE), and is administered by the U.S. Army Engineer Research and Development Center (ERDC), Coastal and Hydraulics Laboratory (CHL), Vicksburg, MS. Mr. Mark S. Roupas is HQUSACE FRM Business Line manager overseeing FCS. Dr. Jeffrey P. Waters was the program manager for CODS, and Dr. Julie Rosati was the Acting program manager for the FCS Program.

The work was performed by the Environmental Systems Branch of the Ecosystem Evaluation and Engineering Division (CEERD-EE), ERDC Environmental Laboratory (ERDC-EL) and the Coastal Observation and Analysis Branch of the Flood and Storm Protection Division (CEERD-HF), ERDC-CHL.

At the time of publication, Mr. Mark Graves was Branch Chief, CEERDEE-C; Mr. Mark Farr was Division Chief, CEERD-EE; Dr. Jeffrey Waters was Chief, CEERD-HFA; and Dr. Cary Talbot was Chief, CEERD-HF. Dr. Julie Rosati was the Technical Director for the Flood and Coastal Systems Research \& Development Programs. The Acting Deputy Director of ERDC-CHL was Dr. Jackie S. Pettway, and the Acting Director was Mr. Jeffrey R. Eckstein.

Permission to publish this information was granted by the Chief of Engineers.

The authors express appreciation to Dr. Safra Altman and Ms. Jennifer Laird for review of the technical report.

COL Bryan S. Green was the Commander of ERDC, and Dr. David W. Pittman was the Director. 


\section{Unit Conversion Factors}

\begin{tabular}{|l|c|l|}
\hline Multiply & By & To Obtain \\
\hline acres & $4,046.873$ & square meters \\
\hline inches & 0.0254 & meters \\
\hline microns & $1.0 \mathrm{E}-06$ & meters \\
\hline
\end{tabular}




\section{Abbreviations}

\begin{tabular}{ll} 
2D & two-dimensional \\
3D & three-dimensional \\
AGC & Army Geospatial Center \\
AGRiP & Association of Governmental Risk Pools \\
AIO & Army Imagery Office \\
AR & Army Regulation \\
C & Celsius \\
C2I & Command and Control Information \\
CHL & Coastal and Hydraulics Laboratory \\
CODS & Coastal Ocean Data Systems \\
COTS & commercial off-the-shelf \\
DEM & digital elevation model \\
DOD & DEM of difference \\
DSM & digital surface model \\
DTM & digital terrain model \\
ERDC & U.S. Army Engineer Research and Development Center \\
FAA & Federal Aviation Administration \\
FCS & Flood and Coastal Systems R\&D Program \\
FRM & Flood Risk Management \\
g & gram \\
GCP & Ground Control Point \\
GIS & Geographic Information System \\
GLCM & grey level co-occurrence matrix \\
GNSS & Global Navigation Satellite System \\
GPS & Global Positioning System \\
GRL & Geospatial Research Laboratory \\
GSD & ground sampling distance \\
IMU & inertial measurement unit \\
IR & infrared \\
kg & kilogram \\
LiDAR & light detection and ranging \\
LRC & Chicago District \\
m & meter \\
mm & millimeter \\
MP & mega pixel \\
MVN & New Orleans District \\
& \\
\hline
\end{tabular}




$\begin{array}{ll}\text { MVS } & \text { St. Louis District } \\ \text { NAB } & \text { Baltimore District } \\ \text { NGA } & \text { National Geospatial-Intelligence Agency } \\ \text { OBIA } & \text { object based image analysis } \\ \text { R\&D } & \text { research and development } \\ \text { RGB } & \text { red green blue } \\ \text { RTK } & \text { real-time kinematic } \\ \text { SAJ } & \text { Jacksonville District } \\ \text { SAW } & \text { Wilmington District } \\ \text { SfM } & \text { structure from motion } \\ \text { SOP } & \text { standard operating procedures } \\ \text { SWG } & \text { Galveston District } \\ \text { UAS } & \text { unmanned aircraft system } \\ \text { ULS } & \text { UAS laser scanning } \\ \text { USGS } & \text { U.S. Geological Survey } \\ \text { YOY } & \text { young of the year }\end{array}$




\section{Introduction}

\subsection{Background - Flood Risk Management (FRM) challenges}

Coastal and riverine shorelines are dynamic landscapes that change continually in response to environmental forces. The combination of static infrastructure with dynamic and diverse landscapes creates management challenges for navigation, storm damage reduction, and ecosystem health that are exacerbated during natural disasters. The U.S. Army Corps of Engineers (USACE) flood risk management (FRM) mission strives to reduce the nation's flood risk and increase resilience to disasters. FRM is inherently interdisciplinary, requiring accurate identification of environmental, physical, and infrastructure features that can reduce risk from flood and coastal storm disasters. For example, healthy ecosystems are a critical component of a coastal and riverine system's ability to both withstand and recover from natural disasters-functions that increase the resiliency of these systems over longer terms.

\subsection{Objective}

USACE has identified a number of research and development (R\&D) opportunities that will help reduce disaster risks, which include (1) identifying better technologies for hazard identification pre- and postevents; (2) developing an interdisciplinary understanding of physical, chemical, and biological recovery processes that occur post-event; and (3) providing shared and easily accessible, up-to-date data sets that can be utilized by flood and coastal storm modeling and predictive tools to inform emergency response. Cost-efficient technology and methodology, such as the use of Unmanned Aircraft System (UAS) technology for accurate, detailed, and timely two-dimensional (2D) and three-dimensional (3D) monitoring of coastal and riverine landscapes, have the potential to address many of these goals. However, an important process in adapting new technologies is ensuring an understanding of existing methods, identifying gaps or shortcomings with current techniques and then developing new approaches and providing guidance and insight on how new tools can address these gaps as well as exploring potential future capabilities. To that end, the USACE Flood and Coastal Systems R\&D Program (FCS) has initiated an effort focused on identifying and developing defendable and consistent UAS-based methodologies and data 
products that can seamlessly integrate with numerical models to improve quantification of the nation's flood risks to coastal and riverine shorelines, infrastructure, ecosystems, and communities.

\subsection{Approach}

This report focuses on identifying the role of UAS technology to support environmental missions and applications, especially those related to flood risk management, within the USACE. While it does not address operational classification, guidance, and policies, which have been established and published (Chairman of the Joint Chiefs of Staff Notice 2012; Code of Federal Regulations 2016; USACE 2016a), this report does evaluate the technical capabilities of UAS support for critical environmental applications within civil works planning, operations, and monitoring practices. Specifically, the report provides a technical review, including District feedback, of USACE-related environmental needs and assesses the role of UAS-based data product research and development.

\subsection{Remote sensing and UAS overview}

Remotely sensed data provide spatial and temporal perspectives on ecological phenomena that would otherwise be difficult to study (Anderson and Gaston 2013). Though traditional air- and space-borne systems provide many advantages, they are often constrained by cost; temporal, spatial, and spectral resolution; and cloud contamination (Loarie et al. 2007). UASs are emerging as flexible platforms that, in many cases, overcome previous constraints and therefore have the potential to supplement or replace measurements acquired from other methods (Whitehead and Hugenholtz 2014). The Federal Aviation Administration (FAA) defines UASs as "unmanned aircraft (operated without the possibility of direct human intervention from within or on the aircraft) and associated elements (including communication links and the components that control the unmanned aircraft) that are required for the pilot in command to operate safely and efficiently in the national airspace system" (Section 333 of Public Law 112-95, 126 Stat.75) (Code of Federal Regulations 2016; FAA 2016). Though the modern unmanned aircraft began as simple instruments for improving battlefield intelligence during the First World War (Blom 2010; Kahvecioglu and Oktal 2016), their design, application, and regulations have become vastly more complex. Major advantages of UASs can be found in the ability to operate in high-risk situations, in inaccessible areas, at low altitudes, and close to 
targets, all without endangering human life (Ma et al. 2013). Recent technological advances in UASs, including the miniaturization of components and improvements in electronics, navigation and telemetry, have resulted in reduced costs and risks, increased efficiencies, and enhanced products and perspectives on projects (Association of Governmental Risk Pools [AGRiP] 2015; Hobbs and Herwitz 2006). These UAS improvements have resulted in a growing service mechanism with widespread application across civil, military, and public sector uses (AGRiP 2015). This is evidenced in the world UAS market spending, which has increased from an estimated $\$ 2.9$ billion in 2005 to $\$ 6-7.5$ billion in 2016 (Ramsey 2005; Lucintel 2011; Kahvecioglu and Oktal 2016).

With increasing deployment worldwide, improving the overall attainability, responsiveness, flexibility, survivability, sustainability, and simplicity of UASs is critical for all purposes (Karaagac et al. 2015). Advances in UAS technology and flight control systems have transformed military-grade fixed- and rotary-wing UASs to research-grade tools capable of many civil and public applications (Klemas 2015). On the civil side, industry and private companies have used UASs for infrastructure inspections, property appraisals, agricultural surveys, commercial aerial photography, commercial fishing, news gathering, and more (AGRiP 2015). For public use, many federal, state, and local government agencies have added UAS capabilities in support of their organizational missions. State and local governments are using UASs in support of search and rescue operations, law enforcement surveillance, fire suppression activities, public safety, weather monitoring, and disaster relief (Kopardekar et al. 2016). Many federal government agencies have begun to establish cost-efficient UAS operations to survey, monitor, inventory, and evaluate many structural, geophysical, biological, and chemical resources (Cress et al. 2015). As a result of the proven utility of UAS technology, researchers continue to explore new and innovative uses.

Though remote sensing is not new to the USACE, advanced techniques have transformed ecological research by providing unique spatial and temporal perspectives on ecological phenomena (Kerr and Ostrovsky 2003) and offer the potential for much higher resolution data at more frequent intervals, enabling scientists to more consistently examine a range of ecological systems (Wulder et al. 2004). Environmental monitoring, especially to evaluate the success of large- or small-scale restoration projects, requires the ability to detect and map land surface 
attributes and landscape level characteristics over time and space. The most practical method for these assessments is through high spatial resolution imagery ( $<5$ meter $(\mathrm{m})$ spatial resolution), either from satellite or airborne platforms. Airborne systems have traditionally been considered the most available, versatile, and widely used means of acquiring remotely sensed data products (Lillesand et al. 2014). For decades, these data sources and products have been routinely used within the USACE for environmental mapping applications. One such program offering high-resolution airborne data products for the USACE is the National Coastal Mapping Program, administered by the Joint Airborne Lidar Bathymetry Technical Center of Expertise (Wozencraft 2010). Operational since 2004, this program collects high-resolution imagery and elevation data for the coastal United States (on a repeat basis) to support a myriad of operational, planning, environmental, and emergency response activities.

Additionally, there are numerous contractors being utilized by the USACE to collect remote sensing data from helicopters and/or fixed-wing aircraft. Since the wide range of capabilities, sensor types, and aircraft platforms is unique to individual contractors and beyond the scope of this report, only a general description for image acquisition and data types is provided. The data types that are available include light detection and ranging (LiDAR, both bathymetric and topographic), hyperspectral imagery, multispectral imagery, thermal imagery, and digital aerial photography. Since contracting for these aerial services can be time consuming and costly, planning coordination and efficient communication are typically required to achieve successful completion.

Electro-optical imagery from space-borne satellites also provides a high-resolution data source for many remote sensing applications but can lack flexibility since acquisition and processing typically requires thirdparty solutions. Sometimes, however, satellite imagery is appropriate for feature characterization or land cover classifications that require image scenes covering large areas. Table 1 lists all of the unclassified, commercial high-resolution satellite imaging platforms commonly available for data archive download or new data acquisition to the USACE.

These high-resolution satellite image sources are available for acquisition at no cost to the USACE through the National Geospatial-Intelligence Agency (NGA) EnhancedView contract, and all acquisitions (archived and 
new data collections) are coordinated through the Army Geospatial Center (AGC) Army Imagery Office (AIO). Army Regulation AR 115-11, per the Army executor for commercial imagery acquisitions, is intended to prevent Army agencies and organizations from duplicating Command and Control Information (C2I) data purchases, institute a repository of select C2I data, and ensure that any Army organization with a command-validated C2I need must forward its requirements to the AGC for research, acquisition, and distribution of the data. The data holdings directly support engineering, planning, and response requirements of the USACE, Army, and DOD activities and allow end-users direct access to commercial imagery products available in various online repositories (e.g., AGC Imagery Library, NGA Imagery Library, and U.S. Geological Survey (USGS) data gateways).

Table 1. Overview of high-resolution (5 $\mathrm{m}$ or higher spatial resolution) satellite imagery sources available to the USACE.

\begin{tabular}{|c|c|c|}
\hline Satellite Imagery & Acquisition Source/Contract & Resolution \\
\hline \multicolumn{3}{|c|}{ Electro-optical } \\
\hline WorldView-1/2/3 & NGA/EnhancedView or USGS via Earth Explorer/CMT & $0.5 \mathrm{~m} / 0.46 \mathrm{~m} / 0.31 \mathrm{~m}$ \\
\hline GeoEye-1 & NGA/EnhancedView or USGS via Earth Explorer/CMT & $0.41 \mathrm{~m}$ \\
\hline QuickBird-2 (Archived) & NGA/EnhancedView or USGS via Earth Explorer/CMT & $0.6 \mathrm{~m}$ \\
\hline IKONOS-2 & NGA/EnhancedView or USGS via Earth Explorer/CMT & $0.8 \mathrm{~m}$ \\
\hline Pleiades $1 \mathrm{~A}$ and $1 \mathrm{~B}$ & AIO/ADL Contract (GeoNorth) & $0.5 \mathrm{~m}$ \\
\hline SPOT 5/6/7 & AIO/ADL Contract (GeoNorth) & $2.5 \mathrm{~m} / 2.0 \mathrm{~m} / 1.5 \mathrm{~m}$ \\
\hline EROS A/B & (ImageSat International, Israel) & $1.8 \mathrm{~m} / 0.7 \mathrm{~m}$ \\
\hline FORMOSAT 2 & Resellers/Vendors (satellite decommissioned) & $2.0 \mathrm{~m}$ \\
\hline CartoSat 2A/2B & Resellers/Vendors (satellite decommissioned) & $0.8 \mathrm{~m}$ \\
\hline Planet/RapidEye & NGA (CIBORG Contract ending April 2017) & $3.0 \mathrm{~m} / 6.0 \mathrm{~m}$ \\
\hline SkySat & Skybox & $0.9 \mathrm{~m}$ \\
\hline \multicolumn{3}{|c|}{ Synthetic Aperture Radar/Lidar } \\
\hline RADARSAT 2 & NGA COMSAR & 3 m (Spotlight Mode) \\
\hline TerraSAR-X/TandemX & NGA COMSAR/AIO-ADL Contract (GeoNorth) & $1 \mathrm{~m}$ \\
\hline cosmo/SkyMed & NGA COMSAR (limited \$) & $1 \mathrm{~m}$ \\
\hline IFSAR/LiDAR & AGC (AIO)/USGS (archived) & varies \\
\hline
\end{tabular}




\section{Review}

\subsection{UASs for environmental applications}

Despite ongoing efforts and improvements, monitoring is still considered a major challenge in anticipating environmental response to hazards, disturbances, and management activities (Delacourt et al. 2009; Papakonstantinou et al. 2016). Remote sensing applications provide alternatives to the often costly and laborious field-based collection methods that have been traditionally used for environmental monitoring (Anderson and Gatson 2013). To help meet the challenges of management and operations activities, UAS technology is increasingly used in the scientific community to supplement or replace those traditional environmental study techniques. In addition to supplementing field data, high-fidelity datasets in geospatial format are likewise employed for seamless integration into a Geographic Information System (GIS), realtime temporal data capture, development and refinement of existing environmental models, and improvement of environmental data statistics used as model inputs. For environmental mapping projects that are smallscale in nature but require high-resolution datasets, UAS-derived data sources can be a practical solution. Additionally, because of the lower flying altitude and customization of UAS platforms with a multitude of sensor capabilities and options, data derived from this source can offer optimal spatial and temporal resolutions while allowing the end-user flexibility to collect and process specialized data and products.

The cost to operate UASs without the need for outsourcing is decreasing while the capabilities of onboard sensors are increasing, making UASderived datasets a desirable and flexible option. Low-cost, commercial-offthe-shelf (COTS) UAS platforms with light-weight inexpensive sensors such as point-and-shoot color cameras coupled with commercially available processing software offer a tremendous number of potential products that are germane to ecological and environmental science (Anderson and Gaston 2013). Concurrent with advances in UAS platform technology, sensing technologies have also advanced in recent years. Thermal infrared (IR) sensors are now common COTS (Sheng et al. 2010), and utilization of multispectral, hyperspectral, and LiDAR sensors are now being employed regularly for environmental and ecological applications (Anderson and Gatson 2013). Advances in computing, such as machine learning (computer-derived rules and classification from training data) 
and structure from motion (SfM-computing 3D geometry of an object or surface from images acquired from multiple viewpoints) have added a new dimension to available data products collected by UAS (Jensen 1996; Fonstad et al. 2013; Longmore et al. 2017). Additionally, opportunities to use fleets of simultaneously deployed swarms of UASs that can overcome the spatial range limitations of a single platform are also on the horizon (Merino et al. 2012). These UAS-based techniques and data are increasingly sought after as primary tools for monitoring and evaluating environmental condition, processes, and recovery.

Moreover, UAS applications now go beyond traditional orthophotography and feature classifications and into high-resolution point cloud generation, 2D and $3 \mathrm{D}$ digital surface models, volumetric measurements, vegetative indices, and automated feature extractions. These data are collectively instrumental in providing function and structure information related to key environmental features. For the coastal zone, the spatiotemporal advantages of UASs provide improved measures of coastlines, swash zones, wrack lines, berm crests, shoreline erosion, volume estimates, and restoration efforts (i.e., beach nourishment) (Papakonstantinou et al. 2016). Other recent environmental-based UAS applications include waterfowl and bird surveys (e.g., Sandhill Crane populations, Greater Sage-Grouse); wildlife and critical habitat surveys (e.g., Pygmy Rabbit habitat); forest structure and sustainable management (e.g., prescribed fire); land surface and land use change and impacts; hydrology and riverine ecosystems (e.g., groundwater discharge, emergent sandbar habitats, stream temperature dynamics, and river restoration); and evaluations of threatened, endangered, and invasive species (USACE 2016b; USGS 2017). UASs have also been deployed for feature or structure inspections related to contour surface mines; $3 \mathrm{D}$ modeling of national monuments; earthquake fault surveys and modeling; dam removal and flood structure inventory; and levee inspections and landslides (USGS 2017). Cress et al. (2015) reported that over a 4-year period (2010-2013), agencies within the U.S. Department of Interior quadrupled their UAS flights and expanded traditional techniques and data to support their environmental missions. Several other federal agencies, including the USACE, have also started exploring UAS capabilities employing both fixed-wing and rotary aircraft to address ecological applications.

Examples of UAS utilization for environmental applications are provided here to illustrate the breadth and technological considerations, benefits, 
and limitations therein. Environmental applications span a wide range of sensor types and processing techniques. Sensors include standard RGB (red, green, blue), multispectral, hyperspectral, thermal, and LiDAR cameras. These UAS-collected data are typically used for image classification, feature extraction, and SfM data products (i.e., 3D models). Recently, an increasing number of researchers have tested the capabilities of UAS products related to disturbance events, riverine and coastal systems, infrastructure assessments, avian surveys, wildlife resources, landscape analyses, and many more environmental applications. Brief overviews and specific case studies of these applications are provided below. The case studies provide specific examples of UAS-based environmental applications that are of specific relevance to USACE ecosystem and flood protection needs.

\subsection{Disturbance assessments}

Disturbance events, whether from natural causes, human activities, or a combination of both, can be intense environmental presses or impacts occurring periodically or over short- or long-time periods and can cause severe alterations to ecosystems (Battisti et al. 2016; Science Encyclopedia 2017). Examples of disturbance events include wildfires, hurricanes, and major floods. The ability to quickly assess, respond, and manage critical resources after a disaster or disturbance event, especially in hard-to-access or high-risk areas, cannot be understated. Adams and Friedland (2011) reviewed multiple case studies of UAS-based data acquisitions for disaster management and risk mitigation. These applications included optical/IR sensors for pipeline inspections after earthquakes (Rathinam et al. 2008), vision-based UAS navigation systems to monitor feature vulnerability (Soleimani et al. 2010), and low-altitude UASs to collect photogrammetric-quality imagery of ephemeral gullies to assess landscape changes for disaster management (Frakenberger et al. 2008).

Ezequiel et al. (2014) provide a disturbance event-based case study where UAS data were used to evaluate infrastructure and environmental damage after Typhoon Haiyan in the Visayas region of the Philippines. Utilizing a fixed-wing aircraft flying at $200 \mathrm{~m}$ altitude and using common RGB cameras (Panasonic Lumiz LX3, Cannon S100, and GoPro Hero3), researchers were able to conduct mapping flights from $30-50$ minutes in duration, covering approximately 4 square kilometers (sq $\mathrm{km}$ ) per survey. Pix4D, a popular UAS data processing software, was used to create a representative orthomosaic from 785 images, covering $1.69 \mathrm{sq} \mathrm{km}$ with a 
ground resolution of 5.13 centimeters (cm) (Figure 1). Though these data were initially used to monitor infrastructure and support rehabilitation efforts, they later proved useful in developing applications for assessing and managing critical ecosystem and agricultural resources that were impacted by the typhoon (Ezequiel et al. 2014).

Figure 1. Orthomosaic created from 785 images captured at $200 \mathrm{~m}$ with a ground resolution of $5.13 \mathrm{~cm}$ using RGB camera. (Courtesy of Ezequiel et al. [2014])

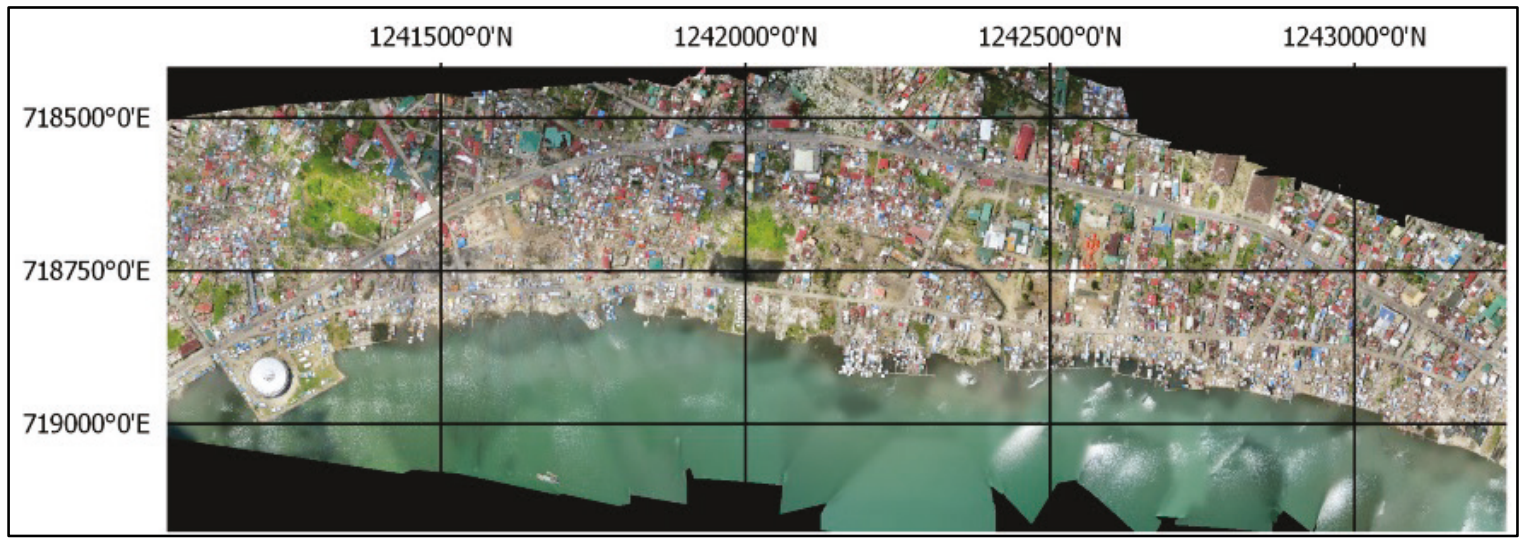

Similar to Typhoon Haiyan in the Philippines, impacts from Hurricane Sandy devastated the eastern coast of the United States in 2012. This area experienced severe inundation and damage from waves that resulted in significant erosion to the shoreline (including USACE project sites) and significant impacts to property, infrastructure, and businesses (Gong 2014). As UAS operations for disaster and disturbance event management become more established, especially as weather systems become increasingly aggressive and natural disasters become more frequent (Karl et al. 2009), it is apparent that more resources will be required to develop novel approaches to assess the vulnerability and resilience of the nation's coastal communities and infrastructure.

\subsection{Riverine and coastal systems}

Severe disturbance events, both natural and human-induced, often have significant impacts on ecosystem structure and function. This is especially true in riverine and coastal systems where hydrological alterations, major floods, and climate events can have long-term physical, biological, and chemical impacts. Whether impacted by natural or disturbance presses or pulses, the monitoring of riverine and coastal systems has been greatly enhanced with recent UAS applications. These applications include mapping of river corridors; coastal geomorphology; bathymetric 
assessments during reservoir drawdowns; hydrological variables and dynamics related to surface water area, depth, temperature, and sediment; and even the collection of biological samples from UASs fit with water pumps (Vericat et al. 2009; Ezequiel et al. 2014; Cress et al. 2015; Higgins 2016; Bandini et al. 2017; Seymour et al. 2017).

Tamminga et al. (2015) provide a case study of the use of UAS surveys (bracketing a major flood event) along the Elbow River, Alberta, Canada, with hydrodynamic models to assess: (1) geomorphic effects of a major flood event, (2) ability of pre- and post-flood data to constrain high flow conditions without knowledge of bed topology, and (3) relationships between simulated flow conditions and patterns of geomorphic change.

Unprecedented flooding between 19 and 23 June 2013 resulted in social, ecological, and physical impacts with estimated losses of $\$ 1.7$ billion (Tamminga et al. 2015). Tamminga et al. used an Aeryon Scout multi-rotor (5 meters per second [m/s]), fit with a three-axis stabilized Photo $3 \mathrm{~S}$ camera with an 8.4 millimeter [mm] lens) for pre-flood survey (September 2012) and a senseFly eBee fixed-wing platform ( $96 \mathrm{~cm}$ wingspan, $10 \mathrm{~m} / \mathrm{s}$ speed, fit with a 16.1 megapixel (MP) Canon IXUS 127 HS camera) for post-flood surveys (September 2013). Surveys consisted of approximately 80\% forward overlap, with 70\% side lap across the flight paths, and the use of 35 Ground Control Points (GCPs) for georegistering. EnsoMOSAIC UAV package and Pix4D software were used for photogrammetric processing of the 2012 and 2013 images, respectively. Processing included automatic aerial triangulation to the referenced GCPs, and bundle block adjustment in an iterative manner to optimize mosaic accuracy. Resulting orthomosaics and Digital Elevation Models (DEMs) had spatial resolutions of 5 and $4 \mathrm{~cm} /$ pixel, for the 2012 and 2013 surveys, respectively (Tamminga et al. 2015). To correct for refractive effects of water, an optical/empirical bathymetric correction was applied, resulting in high vertical accuracy (0.098 $\mathrm{m}$ root mean square error) in submerged areas.

Tamminga et al. (2015) used Geomorphic Change Detection 5.0 software to perform DEM differencing to assess flood-related geomorphic change. Additionally, Nays2DH (2D hydrodynamic model) was used to simulate high flow conditions and investigate relationships to those quantified geomorphic changes. Survey-derived DEMs and DEM of Difference (DOD, due to flooding event) are shown in Figure 2 and were used as model topography $(2 \mathrm{~m} \times 2 \mathrm{~m})$. Figure 2 shows spatial variations in the DOD, 
which reflect infilling of pre-flood low-flow channels and carving of new channels, along with significant bank erosion (Tamminga et al. 2015). By combining UAS-based remote sensing, photogrammetry, and flow modeling, Tamminga et al. were able to characterize $3 \mathrm{D}$ topographic changes and provide insight into the relationship between flood magnitude, channel bed processes, and channel morphodynamics. Ultimately, these and future UAS-based applications will allow for the investigation of riverine processes that would be difficult or impossible to address with more traditional approaches.

Figure 2. Detrended pre- and post-flood DEMs and DEM differencing. Detrended elevations reflect the removal of valley slope and normalization relative to mean reach elevation; positive values are above mean elevation, negative values are below mean elevation. (Courtesy of Tamminga et al. [2015])

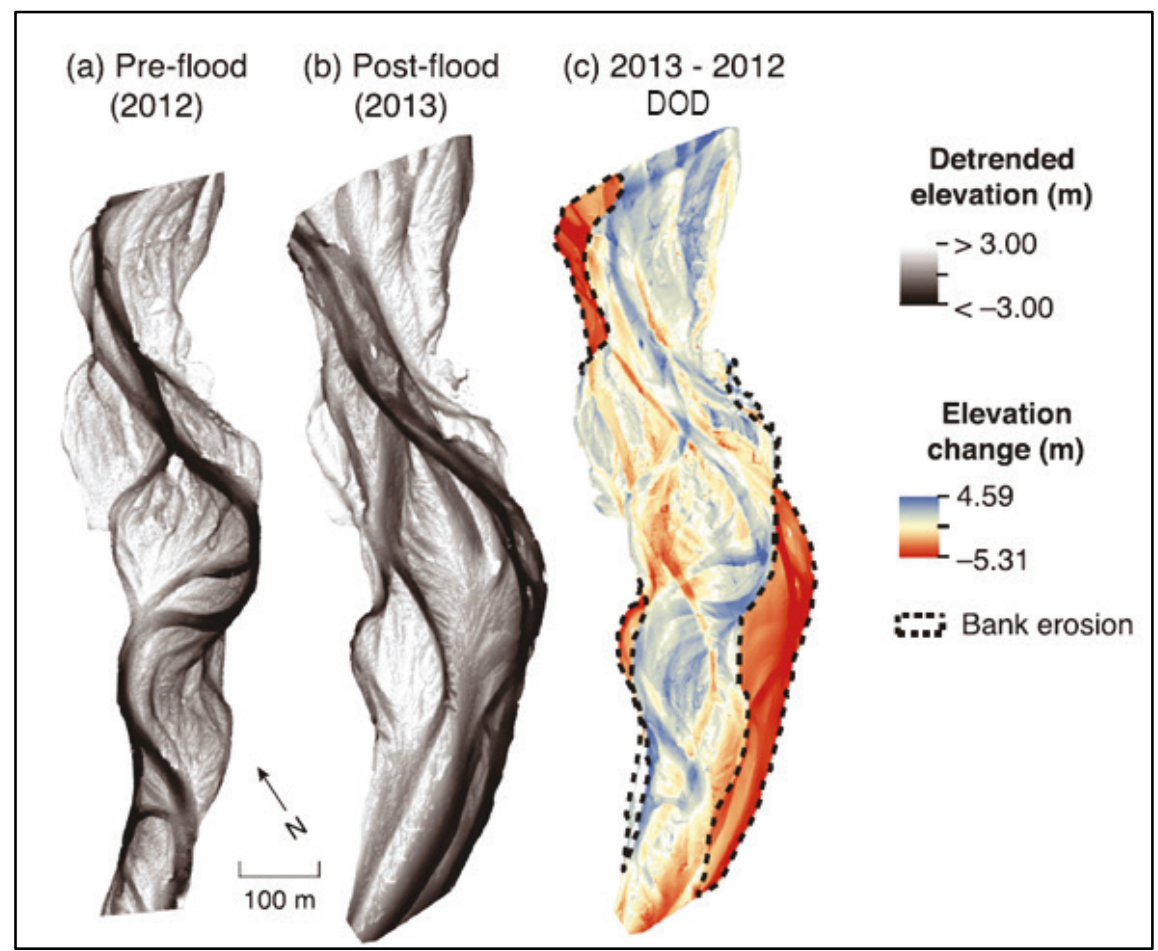

\subsection{Structures}

Since many infrastructure features are surveyed with labor and costintensive methods (traditional Global Navigation Satellite System [GNSS]based surveys along transects) to generate required geometrical parameters (levee height, crown and levee base width, slope, and levee bench width/height), many agencies are evaluating the use of UAS application (i.e., UAS Laser Scanning [ULS]) to provide more efficient methods for monitoring infrastructure (Siebert and Teizer 2014; Bakula et 
al. 2017). Bakula et al. assessed the potential for using a ULS system for $3 \mathrm{D}$ data collection and geometrical parameter generation for levee monitoring. Bakula et al. used a ULS (LiDAR) system to collect and evaluate data along approximately $400 \mathrm{~m}$ of the Dluga River system and levee in Warsaw, Poland. The ULS system consisted of a Hawk Moth multi-rotor (11.5 kilogram (kg) maximum gross weight, $2.5 \mathrm{~m} / \mathrm{s}$ maximum velocity, 15 minutes hovering time) fit with two photogrammetric sensors (YellowScan Mapper laser scanner and the Sony a600o digital camera with a $16 \mathrm{~mm}$ lens). The laser scanner was equipped with a doublefrequency single-antenna GNSS receiver and an Inertial Measurement Unit (IMU) sensor (low-cost) for Real Time Kinematic (RTK) positioning and kinematic azimuth alignment. For all scans, the laser was operated at 905 nanometer wavelength, $50^{\circ}$ maximum scanning angle, $0.125^{\circ}$ angular resolution, and 40 kilohertz frequency. Bakula et al. assessed multiple methods for obtaining satisfactory accuracy while merging point clouds from consecutive flights. These methods included (1) corrected GNSS offset and angles (using precise point positioning techniques), (2) integrated scanlines into one point cloud using the iterative closest point method, (3) 3D transformation, and (4) accuracy enhancement through post processing. Bakula et al. (2017) used these techniques to assess the influence of overlap, vertical accuracy using control points, and ULS applicability for levee monitoring.

ULS data, which were collected from two altitudes (30 and $50 \mathrm{~m}$ ), were used to generate Digital Terrain Model (DTM) data (Figure 3a) that were compared to traditional GNSS ground survey measurements. DTM data were shown to provide multiple advantages over GNSS measurements, including continuity, since they are continuous surfaces, and accuracy, since they represent areas between breaking points (Figure 3b) (Bakula et al. 2017). However, when compared to stereoscopic image-based Digital Surface Models (DSMs, using the image-matching technique), the ULS LiDAR data had slightly worse vertical accuracy at non-vegetated sites. Conversely, the ability for ULS LiDAR to penetrate vegetation and provide bare-earth returns results in significant improvements over image-based DSM data since they cannot provide information about bare ground (Bakula et al. 2017). ULS systems are still in early stages of implementation, and though further refinements in direct georeferencing and system calibration are necessary to match systems with high-cost IMU sensors, they currently provide many advantages over traditional surveys, and their applicability to levee and structure monitoring and assessments will continue to increase. 
Figure 3. Panel A shows the DTM (shaded presentation) of levees in the test area, and Panel B shows a comparison of profiles of the direct field survey (GNSS) and the DTM generated from the UAS. (Courtesy of Bakula et al. [2017])

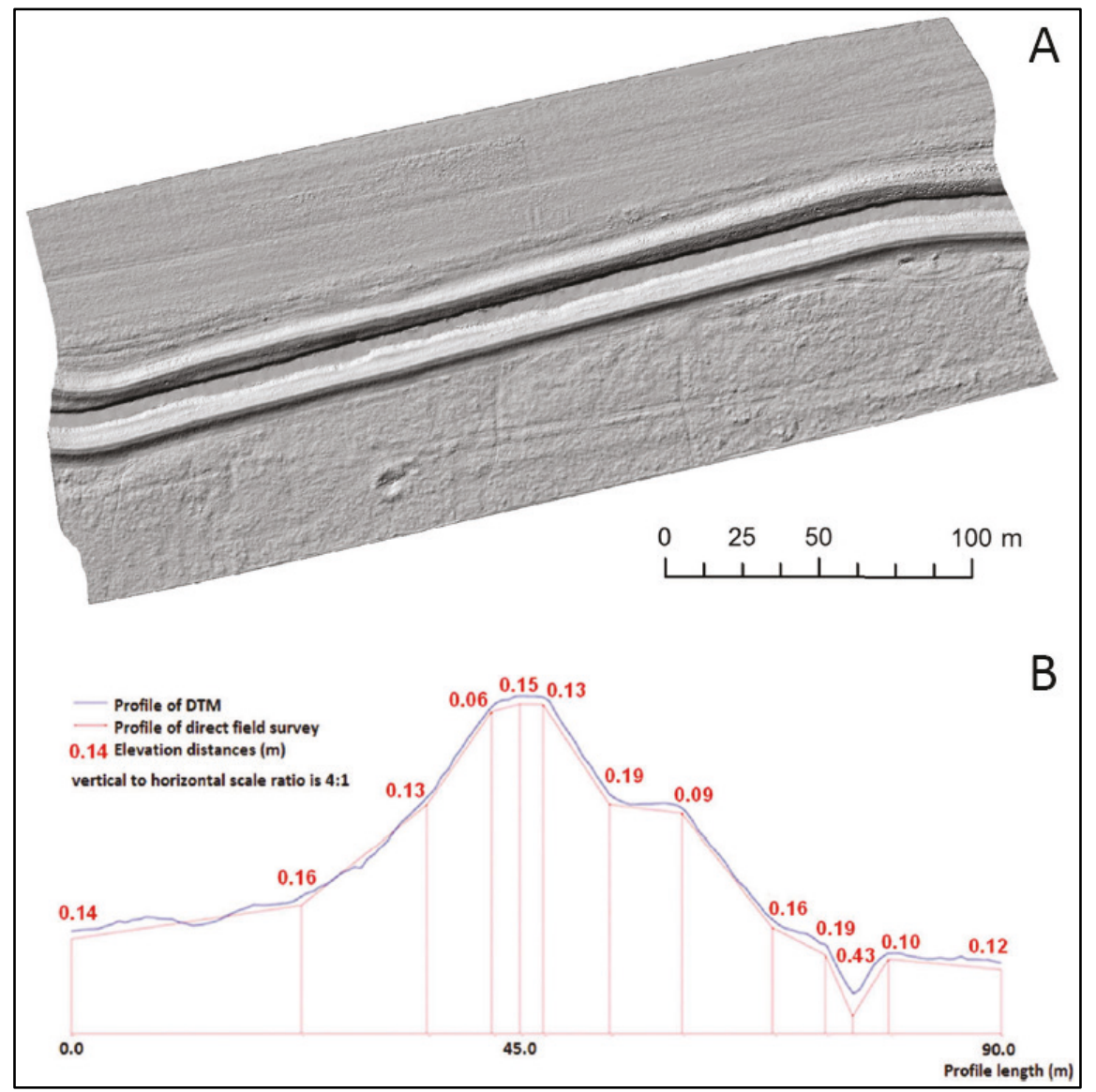

\subsection{Avian}

The ability to conduct wildlife and ecological surveys using unmanned platforms is of increasing interest to many in the ecological, environmental, and biological science communities. This is especially true in the field of avian biology where many surveys are conducted by manned aircraft. Recent advancements in UAS availability, technologies, and techniques have resulted in increasing utilization of those systems to conduct bird counts (i.e., shorebirds and waterfowl) and detect their habitat, especially in hard-to-access areas, smaller geographic areas, and in places where low disturbance is necessary (Chabot and Bird 2012). Early UAS applications for avian biology utilized UASs to evaluate nesting status of canopy-breeding birds, evaluate rookery populations, identify breeding pairs and assess colony size (Sarda-Palomera et al. 2012; Wiessensteiner et al. 2015). UAS may even offer superior precision and accuracy when compared to ground surveys in habitats that are 
particularly challenging to access (Chabot et al. 2014) and when considering data integration and interpretation.

Though remote sensing applications have been successfully used for wildlife and feature detection, the ground sampling distance $(\sim 2 \mathrm{~cm})$ required to detect birds is currently not obtainable with traditional satellite or airborne surveys (Grenzdörffer 2013). In 2013, Grenzdörffer attempted to advance the use of UASs in avian biology by assessing bird disturbance levels to UAS operations, by evaluating the use of UASderived imagery to automate the detection and enumeration of the common gull (Larus canus), and by using UAS-derived elevation models and land cover features to correlate environmental factors with spatial distribution of gulls on Langenwerder Island, Germany. Grenzdörffer found that operating the electrically powered Falcon 8 and MD4-100o multirotor UASs at distances of $15 \mathrm{~m}$ or more above the ground caused no panic or escape behavior in any of the birds present on the island.

To assess the ability of a UAS to detect and count the number of gulls and clutches, Grenzdörffer (2013) utilized UAS-collected high-resolution multispectral imagery and a supervised classification method. This method was used since the white head and light gray plumage of the common gull provides spectral properties that contrast the natural landscape. The Falcon 8 (8-rotor, 400 gram [g] maximum payload, 15-minute flight time, two-axis camera stabilization) and the MD4-1000 (4-rotor, 1,200 g maximum payload, 30-minute flight time, two-axis stabilization) were equipped with Sony NEX $5(4,592 \times 3,056$ pixel resolution) and Olympus PEN E2 $(3,000 \times$ 4,000 pixel resolution) cameras, respectively. Preliminary surveys in 2011 were used to determine that the optimal flight altitude for detecting the 40$45 \mathrm{~cm}$ gulls was $50-55 \mathrm{~m}$ with an associated ground sampling distance (GSD) of approximately $1.6 \mathrm{~cm}$. To better account for rolling movements of the UAS and to enhance the georeferencing procedures necessary for orthophoto creation, Grenzdörffer devised a flight plan with $80 \%$ end lap and a $60 \%$ cross lap. Radial distortion correction and mosaicking of the 2011 (Falcon 8, 50 images) and 2012 (MD4-1000, 629 images) collected imagery were performed using ImageIron and Autopano Giga 2.5, respectively (Grenzdörffer 2013).

RTK Global Positioning System (GPS) control points along only one edge of the island (breeding limited island access) were collected and used to geoposition the images, which were subsequently processed in Pix4D to 
generate digital orthophotos, a DSM, and 3D-point clouds (Grenzdörffer 2013). Grenzdörffer used ArcGIS 10 to perform a supervised classification that generated a seven-class raster image with a birds class consisting of 52,488 objects. The spectrally different head and body of the gulls were often classified as different objects within the birds class, so a distance function was used to combine features that were less than $24 \mathrm{~cm}$ apart. Additionally, objects smaller than $10 \mathrm{~cm}^{2}$ (e.g., small bright stones) and larger than 2,000 $\mathrm{cm}^{2}$ (e.g., larger bird species) were omitted. A visual assessments of the remaining bird objects (1,568 and 1,945 for 2011 and 2012, respectively) (Figure 4A) were performed to determine the accuracy of the supervised classification method. The assessment showed that $95.4 \%$ (2011) and 97.6\% (2012) of the bird objects were classified correctly, with the higher accuracy in 2012 being attributed to higher image quality (image blur due to wide-angle lens of the Sony $\mathrm{NEX}_{5}$ ). The incorrectly classified objects consisted primarily of wood and stone or were instances where birds were located close together or in shaded areas (Grenzdörffer 2013).

Figure 4. Panel A shows the automatic software identification of a bird, Panel $B$ shows the calculated canopy height from the 3D cloud, and Panel C shows the DSM for Langenwerder Island. (Courtesy of Grenzdörffer [2013])

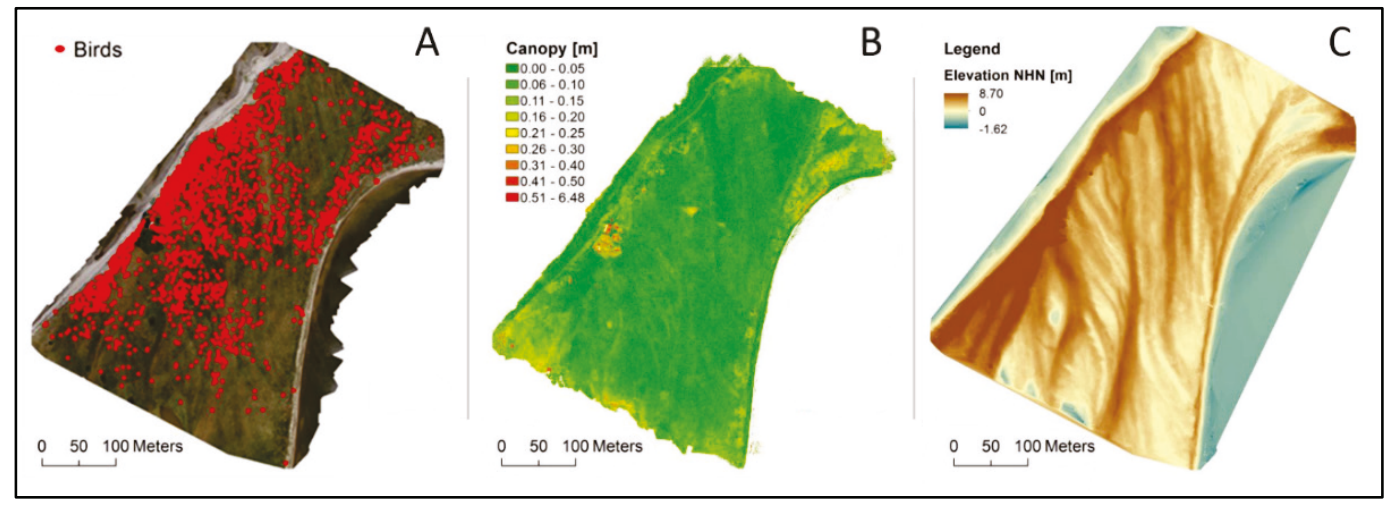

Since gulls typically nest in sparsely vegetated areas that have decreased potential for flooding, weather impacts, and access from terrestrial predators, Grenzdörffer (2013) evaluated the use of UAS-derived orthophotos, digital surface models (DSM), and 3D point cloud data to assess correlations between geomorphology (site characteristics) and spatial distribution of gulls. Point clouds (6.8 cm average spacing and 215 points/ $\mathrm{m}^{2}$ density) were analyzed using LAStools/lascanopy, and extreme outliers (two times standard deviation) were removed to best represent canopy height (Figure 4B). These data provide a first-pass suitability assessment since gulls favor locations of nests that are in low vegetation (Grenzdörffer 2013). Additionally, since gulls seek their breeding sites in dry, non-flood 
endangered areas, a bare-earth DEM was generated to identify areas where heavy rainfall or high tide may cause wet grounds or local flooding (Figure 4C). These examples demonstrate a few novel UAS applications that have been used in avian and avian habitat research.

\subsection{Wildlife}

As with avian applications, UASs provide many advantages over traditional wildlife and marine research methods. With recent advances in system technology and techniques, there have been significant increases in UAS applications for wildlife monitoring and assessments (Christie et al. 2016). These include, but are not limited to, automatic localization and counting of animals, evaluation of spatial ecology of estuarine reptile nesting, mapping of coastal fish nursery grounds, tracking of radio-tagged Asian carp, and identification of mechanisms of mammalian distribution (Lisein et al. 2013; van Gemert et al. 2014; Evans et al. 2016; Ventura et al. 2016).

Species abundance, which is often directly or indirectly estimated with the use of post-processed remote sensing surveys, is important to evaluate a species' role or impact within an ecosystem (Seymour et al. 2017). Advances in thermal imaging sensors (thermal IR detectable ranges are $\sim 3.0-14.0$ microns $[\mu \mathrm{m}]$ ) on board UASs allow for increased identification of many mammals, especially those that were previously difficult to detect (e.g., small and nocturnal animals) with standard aerial surveys (Israel 2011). Recent studies have capitalized on steep thermal gradients between mammalian targets (9-14 $\mu$ m wavelengths), and their backgrounds, to identify populations (Seymour et al. 2017). Coupling thermal imaging sensors with source detection models have also been shown to automatically identify and enumerate large mammals (Longmore et al. 2017). Seymour et al. provide a useful case study of the automated detection, differentiation, and enumeration of adult and pup (young of the year [YOY]) grey seals (Halichoerus grypus) at two breeding colonies (Hay Island and Saddle Island) in the Gulf of St. Lawrence, Nova Scotia, Canada, using UAS and thermal imagery.

Seymour et al. (2017) used a senseFly eBee UAS (fixed wing, single brushless electric motor, $96 \mathrm{~cm}$ wingspan, $0.7 \mathrm{~kg}$ weight, $36-57 \mathrm{~km} / \mathrm{hour}$ speed) fitted with Canon S110 (12 MP RGB) and senseFly Thermomapper $(640 \times 512$ pixel thermal IR sensor) cameras to conduct surveys at each colony. The RGB imagery (1/200oth shutter speed and $3 \mathrm{~cm}$ ground sampling resolution) was collected approximately every 3 seconds while the 
self-calibrating thermal sensor $\left(0.1^{\circ} \mathrm{C}\right.$ marketed precision, $1{ }^{\circ} \mathrm{C}$ groundverified precision, and $8 \mathrm{~cm}$ ground sampling resolution) was collected at sub-second intervals (Figure 5) (Seymour et al. 2017). Each hand-launched and guided flight (fit with high-resolution barometer as well as GPS and wind-speed sensors) was pre-programmed using eMotion 2 software and recovered after a linear landing at a predetermined $5 \mathrm{~m}$ radius location.

Figure 5. A thermal infrared spatial index map (A) and a representative individual thermal IR image

(B) of the grey seal colony at Hay Island, NS, Canada. This footprint of the individual image is projected onto the spatial index, providing a detailed view of adult and YOY grey seals and the habitats surveyed (rock, beach and frozen ground). This map was created with ArcMap GIS software (version 10.4.1, ESRI Inc.). (Courtesy of Seymour et al. [2017])

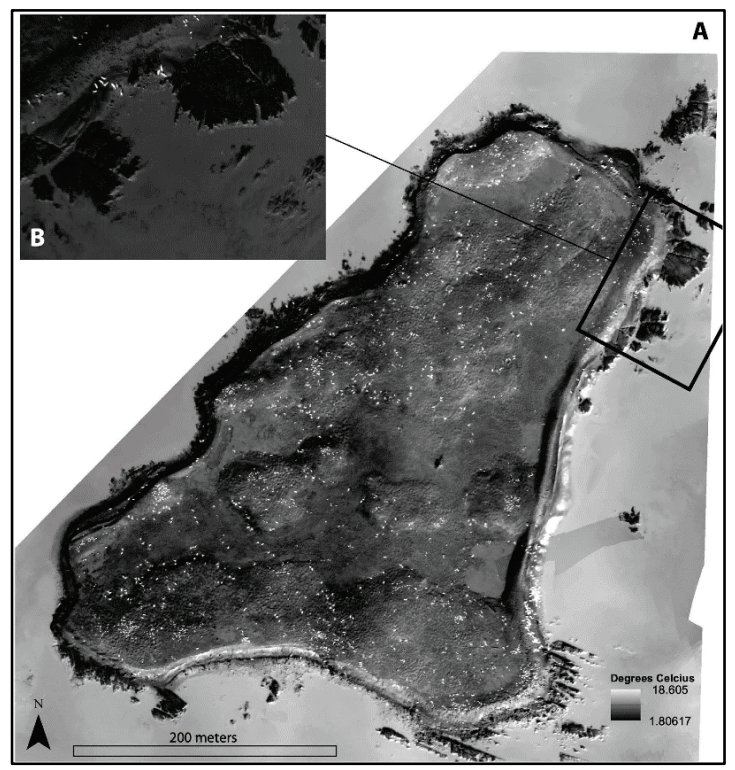

The UAS-collected images were processed using the Pix4D software package to create RGB orthomosaics and temperature index GeoTIFFs. These products were then used by human analysts to manually identify adult and YOY seals (Figure 6A). An automated detection tool was created in the ArcGIS model builder programming environment (Version 10.4.1, ESRI Inc.) and evaluated using Hay Island data. This tool used spectral thresholds and pixel cluster size sorting to differentiate grey seal adults from YOY and integrated object recognition and high pass filtering (i.e., edge detection) to discriminate individuals within closely packed aggregations (Seymour et al. 2017). Seymour et al. selected all thermal pixels greater than or equal to $9{ }^{\circ} \mathrm{C}$ (seal temperature threshold based on 
visual observations), converted those to polygons, and computed the area and average temperature of each (Figure 6B). Seymour et al. also used a ratio between original polygon features and constructed convex hulls to separate individual seals from those that were touching in aggregation, and size and temperature variations to discriminate adult from YOY (Figure 6C and D).

Figure 6. (A) Thermal imagery with overlaid human-identified seal points (red=YOY, green=adult). (B) Red seal polygons outlined by blue convex hulls. (C) Tier 1 model classification of seals. Blue polygons are adult aggregations, orange polygons are YOY aggregations, green polygons are individual adults and red polygons are individual YOYs. (D) Aggregation polygons after highpass filtering, broken up into individual adults and YOYs.

(Courtesy of Seymour et al. [2017])

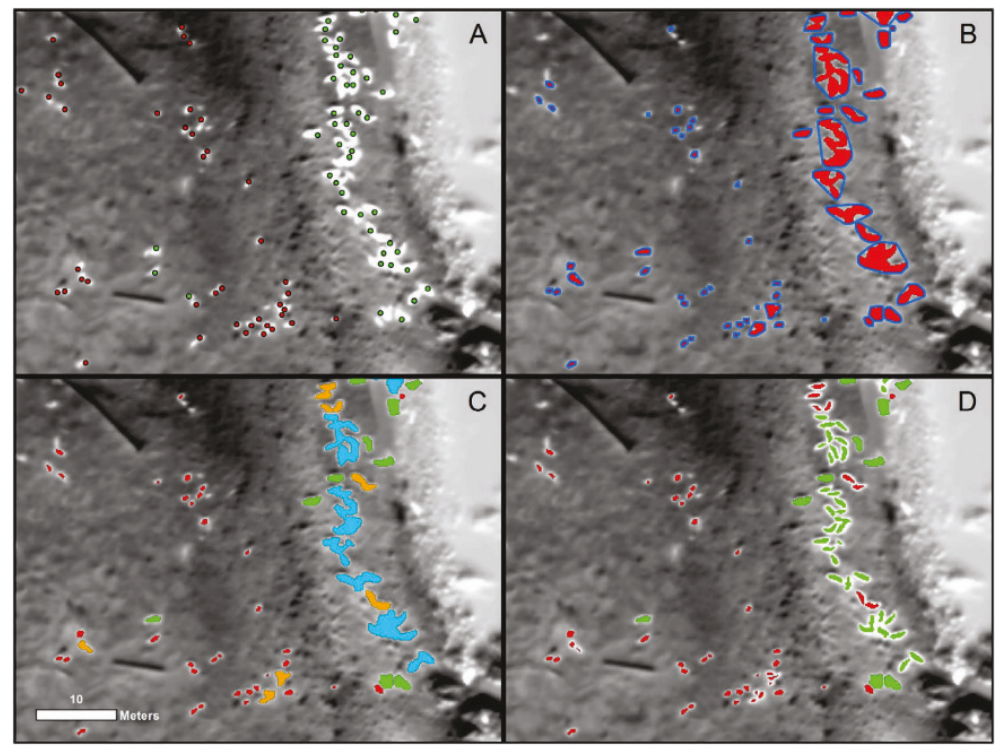

The preliminary method that was developed for Hay Island was modified and applied to the Saddle Island site. Two variants were applied: (1) a simplified version, which omitted temperature, and (2) the original complex version with a lower temperature threshold to account for ambient landscape temperatures. For accuracy assessments, model predictions were compared to human-identified adult and YOY seals. Total seal counts between the methods were $\sim 95 \%$ and $\sim 98 \%$ accurate at the Hay and Saddle Islands, respectively, regardless of model method. The two methods were also very similar in their sub counts of YOYs and adults, though the model slightly undercounted seals when compared to traditional methods, missing a small number of animals that were below the chosen lower temperature detection threshold. Though the total seal counts were similar, the simple and complex models binned adults and YOY differently, with the complex 
classification better accounting for age with use of the thermal data. This study provides a compelling example of how small UAS-collected thermal data can be integrated with GIS machine-based methods to automate (with only site-specific temperature thresholds) the detection, differentiation (based on size/age), and count of animals.

\subsection{Landscape}

UASs have also been used recently to evaluate and monitor landscape and vegetation dynamics. Some notable UAS-based landscape applications include 3D landscape modeling, monitoring phenology of floodplain grasslands and herbaceous vegetation, remote sensing of submerged aquatic vegetation, assessing biodiversity of tropical rainforests, quantifying tree canopy-gap and floristic biodiversity, and species level classifications (Koh and Wich 2012; Flynn and Chapra 2014; Getzin et al 2014; PanequeGalvez et al. 2014; Zarco-Tejada et al. 2014; Tang and Shao 2015; Van Iersel et al. 2016). Textured image processing has also been used to differentiate ecological communities (Laliberte and Rango 2009). This is especially important in riparian zones, which are key landscape features with exceptionally rich biodiversity and important ecosystem services especially for flood protection (Michez et al. 2016). Assessing the distribution and condition of riparian features and species has typically been accomplished using very-high-resolution air- and space-borne imagery (Müllerová et al. 2005; Fernandes et al. 2014). However, acquiring adequate resolution data during important and specific phenological stages (i.e., differentiation of plants due to flowering), especially for the identification of invasive plants, can be difficult with traditional means.

Though the use of UAS for invasive species identification and mapping is promising, especially with regards to phenological stage, few studies are found in the literature. As a result, Michez et al. (2016) evaluated the use of UAS imagery and supervised classification (based on random forests algorithms) to determine optimal variables (using object based image analysis [OBIA]) for identification of three riparian invasive species (Fallopia sachalinensis, Impatiens glandulifera, and Heracleum mantegazzianum) in the Berwinne $\left(2 \mathrm{~km}^{2}\right)$ and Orneau $\left(8 \mathrm{~km}^{2}\right)$ valleys, Belgium. Image-objects represent meaningful entities or scene components that are distinguishable in an image and are typically based on image segmentation (whether pixel-, edge-, or region-based) (Blaschke et al. 2014). Michez et al. used a Gatewing X100 UAS (100 cm wingspan; $2 \mathrm{~kg}$ weight; $80 \mathrm{~km} /$ hour speed; and 45 minute flight time) with two pre- 
calibrated Ricoh GR3 cameras (RGB and near-IR; $10 \mathrm{MP} ; 6 \mathrm{~mm}$ focal length, 1/200o shutter speed, and 75\% overlap) for aerial photo acquisition. UAS images were acquired during the flowering period for I. glandulifera and $H$. mantegazzianum, and the leaf-yellowing period for $F$. sachalinensis (Figure 7A). Agisoft Photoscan 1.o professional, with Mosaic blending and color correction modes, was used to generate orthophotos $(0.1 \mathrm{~m}$ and $0.05 \mathrm{~m}$ GSD). Field surveys were used to create a set of georeferenced training polygons of study area invasive species (Figure $7 \mathrm{C}$ ).

The segmentation of UAS orthophotos was performed with the eCognition developer software with a multi-resolution image segmentation algorithm using four scale parameters $(10,30,45$, and 60 ; related to the object size) and two homogeneity criteria values ( 0.1 for shape and 0.5 for compactness) (Figure $7 \mathrm{~B}$ ). Metric extraction was performed using five Grey Level Co-occurrence Matrix (GLCM) derivatives (entropy, standard deviation, correlation, mean, and contrast) in an all-direction approach. Supervised classifications were based on a random forests algorithm.

The results of these methods showed that the highest accuracies were achieved with the lowest segmentation scales (i.e., 10), and that although spectral metrics were the dominant metrics, the texture metrics (GLCM derivatives) did add accuracy to the classification model. The model for H. mantegazzianum was considerably more accurate (Kappa index of 92\%) than similar remote sensing studies ( $77 \%$ by Müllerová et al. 2013) (Figure $7 \mathrm{D}$ ). However, due to the co-existence and intermixing of native species, the results obtained for I. glandulifera and $F$. sachalinensis were not adequate for operational applications. However, the intermixing of native and invasive species could potentially be overcome with the use of unsupervised classification methods and a similar fine OBIA segmentation. Ultimately, the Michez et al. (2016) approach provides cost-effective and highly accurate classification models that require only minor inputs (few umbels). 
Figure 7. Methods for generating sample datasets: (A) represents the UAS orthophoto (RGB); (B) the multi-resolution segmentation; (C) the reference polygons dataset; and (D) the selected invasive plant species objects (H. mantegazzianum). (Courtesy of Michez et al. [2016])
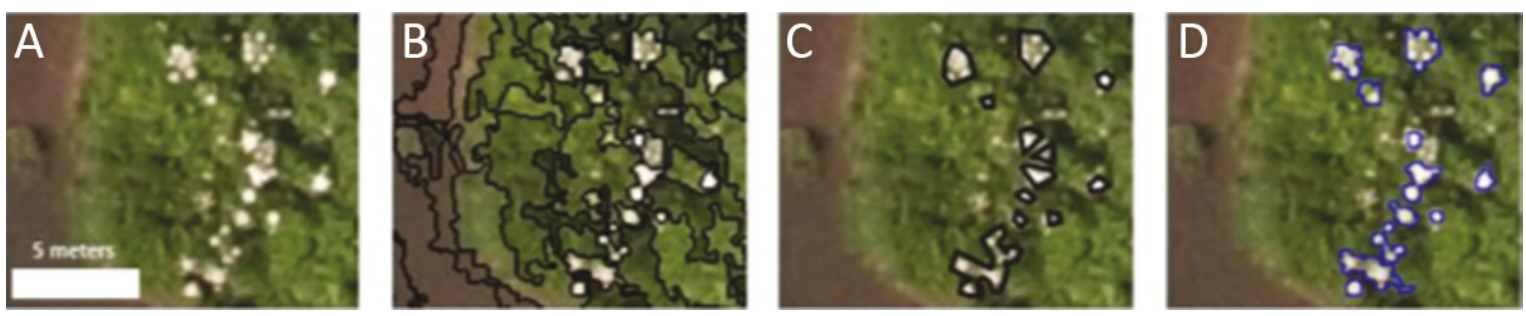

\subsection{USACE considerations}

\subsubsection{Questionnaire}

With the rise of UASs within the USACE, new opportunities exist for UAS technology to strengthen current techniques for assessing indicators of ecosystem health. Integration of UAS technology within the current suite of high-resolution, airborne- and satellite-based data products will offer flexibility and individualized options that may be especially appropriate for site-specific and project-level needs. To maximize the benefits of UASs for environmental applications within the USACE, more detailed information is needed to learn about current practices and usage. Thus, a feedback questionnaire with contextual information was sent to designated persons of interest at various districts as well as a U.S. Army Engineer Research and Development Center laboratory based on their known experience and use of UASs. Feedback was also solicited through the Coastal Working Group, and responses were received in December 2016 and January 2017 from the following USACE groups: Wilmington (SAW), St. Louis (MVS), New Orleans (MVN), Jacksonville (SAJ), Chicago (LRC), Geospatial Research Laboratory (GRL), Galveston (SWG), and Baltimore (NAB). This is not a comprehensive list of all UAS usage within the USACE but represents a sampling of some of the more long-standing efforts, with emphasis on district usage, to better understand current field activities and needs. The following represents the questions and summarized responses from the feedback questionnaire:

1. Does your district or division use or operate UASs? (yes/no)

a. If yes, please provide information related to the type of platform and sensor, what data products or maps are developed with the data, and key lessons learned, hurdles, etc. If relevant to your work, please provide specific information on how these systems are used to create environmental data products. 


\section{b. If no, what barriers exist that prevent your district or division from using UAS technologies? How do you think UASs could be useful to your work?}

\begin{tabular}{|c|c|}
\hline District/Lab & Response Summary \\
\hline \multirow{3}{*}{ SAW } & * Policy/process is prohibitive \\
\hline & * Time and resource commitments exceed payoff to fly UAS \\
\hline & * Would like to fly if process was simplified \\
\hline \multirow{3}{*}{ MVS } & * Utilize fixed wing - Nova \\
\hline & $\begin{array}{l}\text { * Biggest hurdle is Airworthiness Release (AWR) and Certificate of Authorization turn- } \\
\text { around time }\end{array}$ \\
\hline & * Aerial imagery is primary product \\
\hline \multirow{5}{*}{ MVN } & * Utilize fixed wing - eBee RTK \\
\hline & * Utilize multirotor - Albris, Phantom \\
\hline & * Have deployed RGB, IR, and thermal sensors \\
\hline & * Producing orthos, DSM, point clouds \\
\hline & $\begin{array}{l}\text { * Used for environmental monitoring of beneficial use projects, evaluating a } \\
\text { hydraulic model, and identifying bird/animal species }\end{array}$ \\
\hline \multirow{4}{*}{ SAJ } & * Operational since 2009 \\
\hline & * Operates four platforms \\
\hline & * Various RGB sensors, FLIR Vue Pro, and DJI (Phantoms) \\
\hline & * Frame-based processing software varies with mission requirements \\
\hline \multirow[b]{2}{*}{ LRC } & * Policy/process is prohibitive \\
\hline & $\begin{array}{l}\text { * Would like to utilize UAS for topographic surveys, monitoring for flood } \\
\text { operations, and dam inspections }\end{array}$ \\
\hline \multirow{5}{*}{ GRL } & $\begin{array}{l}\text { * Use Buckeye manned aerial system for super-resolution }(<10 \mathrm{~cm}) \text { imagery and } \\
\text { LiDAR) to support civil and military applications }\end{array}$ \\
\hline & * Just beginning to move forward with UAS \\
\hline & * Have cooperated with SAJ to collect imagery for invasive plant species \\
\hline & * Biggest hurdle is small footprint of UAS \\
\hline & $\begin{array}{l}\text { * Altering spectral, spatial, and temporal analysis to support testing and } \\
\text { transition of super-resolution UAS-derived products }\end{array}$ \\
\hline \multirow{3}{*}{ SWG } & * Utilize fixed wing - eBee \\
\hline & * Loss of pilot due to promotion - trained personnel \\
\hline & * AWR is issue as they are not permitted to fly where then need to fly \\
\hline \multirow[t]{2}{*}{ NAB } & $\begin{array}{l}\text { * Run out of Audio Visual Office - generic media purposes such as wildlife footage } \\
\text { in wetland sites }\end{array}$ \\
\hline & * Not used for mapping \\
\hline
\end{tabular}


2. Who operates the UAS in your district or division and who develops the data products? (internal/external assistance provided?)

\begin{tabular}{|c|c|}
\hline District/Lab & Response Summary \\
\hline SAW & * SAJ has been tasked to fly, but can be costly \\
\hline \multirow{2}{*}{ MVS } & * Have internal UAS team for collection and processing \\
\hline & * Contract with UAS firms \\
\hline \multirow{2}{*}{ MVN } & * Internal operations within Survey Section \\
\hline & * Unsure who approved UAS contractors are and the process/guidelines \\
\hline \multirow{4}{*}{ SAJ } & * Internal - Full-time UAS section within Surveying and Mapping Section \\
\hline & * Perform UAS training to district users \\
\hline & $\begin{array}{l}\text { * Data products developed by UAS Section (whereas exploitation/analysis done } \\
\text { by end-user) }\end{array}$ \\
\hline & $\begin{array}{l}\text { * Dissemination of image mosaics from a web-based image service (with } \\
\text { Geomatics Section) }\end{array}$ \\
\hline LRC & $\begin{array}{l}\text { * Contracted UAS acquisitions } \\
\text { * Made inquiries to LRH for using their UAS capabilities }\end{array}$ \\
\hline GRL & * Internal operations (GRL Applied Remote Sensing Research Team) \\
\hline SWG & * Hydrology and Hydraulics Section leads UAS activities \\
\hline NAB & * Run out of Audio Visual Office \\
\hline
\end{tabular}

3. Does your district or division use any guidance documents, or have an SOP, for creating GIS data products from UASs or other remote sensing systems?

\begin{tabular}{|l|l|}
\hline District/Lab & Response Summary \\
\hline \multirow{2}{*}{ SAW } & $\begin{array}{l}\text { * Had a proof-of-concept demonstration for incorporating UAS technology into a } \\
\text { production environment with good results }\end{array}$ \\
\cline { 2 - 2 } & * Guidance has deterred pursuing UAS for operations \\
\hline MVS & * No guidance documents or standards \\
\hline \multirow{2}{*}{ MVN } & * Internal SOP and internal survey standards \\
\cline { 2 - 2 } & * Use COTS software and data processing methods \\
\hline \multirow{2}{*}{ SAJ } & * Has standards for UAS Operations \\
\cline { 2 - 2 } & $\begin{array}{l}\text { * Most GIS/remote sensing software not suitable for photogrammetric } \\
\text { processing of UAS frame based imagery }\end{array}$ \\
\hline LRC & * No set standards; determined by the end-user \\
\hline GRL & * No set standards; determined by the end-user \\
\hline SWG & * Working with ESRI to develop product workflows \\
\hline NAB & * No guidance documents or standards \\
\hline
\end{tabular}


4. What high-resolution, environmental data products does your team consistently or sporadically need? "High Resolution" can be high temporal, spectral, or spatial resolution. Do you think UASs would be a good technical solution to help gather that information?

\begin{tabular}{|c|c|}
\hline District/Lab & Response Summary \\
\hline \multirow{3}{*}{ SAW } & * Most data requirements are satisfied through satellite imagery program \\
\hline & $\begin{array}{l}\text { * If restrictions were eased, UAS could be helpful to supplement data collection } \\
\text { efforts }\end{array}$ \\
\hline & $\begin{array}{l}\text { * Product examples include high resolution orthoimages and digital surface } \\
\text { models }\end{array}$ \\
\hline \multirow{2}{*}{ MVS } & * High resolution products such as surface models \\
\hline & * UAS would be a good solution for environmental data products \\
\hline MVN & $\begin{array}{l}\text { * Products include high temporal and spatial resolution, such as } 0.5 \text { - to 3-inch } \\
\text { imagery }\end{array}$ \\
\hline \multirow[b]{2}{*}{ SAJ } & * Customers find value in high spatial and temporal resolution data \\
\hline & $\begin{array}{l}\text { * Product examples include high resolution orthoimages, point clouds, digital } \\
\text { surface models, and 3D models }\end{array}$ \\
\hline LRC & * Data products useful for topographic and photographic applications \\
\hline \multirow{2}{*}{ GRL } & $\begin{array}{l}\text { * Typical products include high spatial and medium spectral resolution imagery } \\
\text { and point-cloud derived surface terrain products for feature extraction and } \\
\text { terrain analysis research }\end{array}$ \\
\hline & $\begin{array}{l}\text { * UAS data becoming a standard data source best applied over small to very } \\
\text { small areas of operation }\end{array}$ \\
\hline SWG & * Primary products are digital elevation models; also used for levee inspections \\
\hline NAB & $\begin{array}{l}\text { * Preferred products would include multispectral imagery (similar to WorldView- } \\
2 \text { or 3), digital elevation models (with 2- to 3-inch vertical accuracy), thermal sensor, } \\
\text { and bathymetric sensor }\end{array}$ \\
\hline
\end{tabular}

\section{How do you envision the development of UAS technology and associated data products improving your ability to accomplish missions?}

\begin{tabular}{|l|l|}
\hline District/Lab & Response Summary \\
\hline \multirow{4}{*}{ SAW } & $\begin{array}{l}\text { * Coastal Storm Damage Reduction projects requiring high accuracy, high } \\
\text { resolution imagery and elevation data }\end{array}$ \\
\cline { 2 - 2 } & * Coastal/beach studies for quantifying sand \\
\cline { 2 - 2 } & * Studies requiring high-resolution data for managing dredge material \\
\hline \multirow{2}{*}{ MVS } & * Provides cost savings when it is cost prohibitive to fly using traditional methods \\
\cline { 2 - 2 } & * Provides a quick way to mobilize, collect data, and generate a surface model \\
\hline MVN & * Support for flood and emergency response as well as civil works mission \\
\hline
\end{tabular}




\begin{tabular}{|l|l|}
\hline District/Lab & Response Summary \\
\hline \multirow{2}{*}{ SAJ } & $\begin{array}{l}\text { * Expects to see the technology mature over time, not requiring the specific } \\
\text { expertise currently necessary }\end{array}$ \\
\cline { 2 - 3 } & * Specialized services/providers will still have a role in data collection \\
\hline \multirow{2}{*}{ LRC } & $\begin{array}{l}\text { * Customers gain higher situational awareness from UAS products than other } \\
\text { platforms }\end{array}$ \\
\cline { 2 - 3 } & * Cost and time savings compared to contracting options \\
\hline \multirow{2}{*}{ GRL } & $\begin{array}{l}\text { * Collection in high-risk or inaccessible areas } \\
\text { over large areas }\end{array}$ \\
\hline SWG & $\begin{array}{l}\text { * Provides improved accuracy and precision of feature extraction and terrain } \\
\text { analytics }\end{array}$ \\
\hline NAB & * Faster capacities and inspections in near real time \\
\hline
\end{tabular}

6. Additional Feedback: please leave your thoughts here. If you would like to be involved and contribute to a review report, please let us know.

\begin{tabular}{|l|l|}
\hline District/Lab & Response Summary \\
\hline SAW & * Tremendous potential to geospatial capabilities, but policy is a roadblock \\
\hline MVS & * Interested in participating in report reviews \\
\hline MVN & * Has some experience and is interested in working with partners \\
\hline \multirow{3}{*}{ SAJ } & * Has the most district experience \\
\cline { 2 - 3 } & $\begin{array}{l}\text { * Authored UAS guidance Engineering Manual 1110-1-106; working on } \\
\text { Engineering Manual for UAS operations }\end{array}$ \\
\hline \multirow{2}{*}{ LRC } & $\begin{array}{l}\text { * The technology offers many benefits and the USACE must find } \\
\text { reasonable ways to use it }\end{array}$ \\
\hline \multirow{2}{*}{ GRL } & $\begin{array}{l}\text { * Interested in participating in any related review groups for current/future UAS } \\
\text { research }\end{array}$ \\
\hline SWG & * Interested in participating in report reviews \\
\hline \multirow{5}{*}{ NAB } & * Interested in participating in report reviews \\
\cline { 2 - 3 } & $\begin{array}{l}\text { * Has been working with multispectral imagery, aerial photography, and LiDAR } \\
\text { for vegetation differentiation and health and subsurface heat analysis on a } \\
\text { major wetland project for } 6 \text { to } 7 \text { years; inclusion of UAS will be important for } \\
\text { future remote sensing work }\end{array}$ \\
\cline { 2 - 3 } & * Interested in bathymetric capabilities for small tributaries and turbidity issues \\
\hline
\end{tabular}




\subsubsection{Discussion}

The heightened and growing application of UAS technology for environmental and infrastructure monitoring demonstrates the potential value for fulfilling management needs (Christie et al. 2016). Five of the eight USACE groups that provided feedback to the questionnaire currently operate UASs for some aspect of their environmental mission. Those that do not operate UASs stated the desire to incorporate UAS applications into their workflow, but policy, process, technical limitations, and cost are primary constraints. Like other environmental managers and stakeholders, USACE groups typically face a trade-off between the performance of the materials, the logistics, and the investment, which explains why most that utilize UASs do so with relatively small and inexpensive systems (Linchant et al. 2015). While USACE groups with UAS capabilities collect data for a myriad of purposes (ranging from traditional photo acquisition to higher spatial, spectral, and temporal collections for flood protection and dam inspections), those without UAS capabilities have relied on other USACE districts or private sector firms to provide UAS-based products. Of the five USACE groups that operate UASs, only two currently have standard operating procedures (SOPs) and survey standards for creating geospatial data products from UASs or other remote sensing systems. SOPs and guidance documents are important since they are expected to overtake technological limitations as the primary constraint for future UAS usage (Vincent et al. 2015). Regarding future development of UASs and incorporation into USACE procedures, most groups see the increase in situational awareness from UAS products as a major advantage. Additionally, the possibility of automatic detection and classification of coastal features, terrain analytics, flood and emergency response, and the monitoring of operations and maintenance activities (i.e., dredge material placement) are important developments for future use in USACE. 


\section{Conclusion}

With near-term technological improvements (increased distance, accuracies, and resolution of data collections), UAS applications will likely become increasingly popular in environmental monitoring and research (Christie et al. 2016). This will be especially true for assessing current state of ecosystem and infrastructure resources before and after management activities, disturbance events, and natural disasters. As such, the improvements in data fidelity will likewise benefit storm impact assessments and predictive modeling capabilities to support flood risk management. UAS technology has much promise as a scientific monitoring tool but only when combined with appropriate sensors, established sampling protocols, targeted groundtruthing efforts, and statistical analysis (Jones et al. 2006). Integration of UAS technology in a multi-sensor framework offers much needed flexibility and low-cost options for not only assessing ecosystem and infrastructure condition but also for evaluating resource vulnerability. As with any new science and technology, long-term capabilities and limitations are often unknown. Therefore, continued advancements in UAS remote sensing capabilities are required to improve USACE awareness and application for navigation infrastructure, storm damage reduction projects, and ecosystem health assessments. Research and development should drive future work by continuing to identify and assess the latest UAS technology, sensors, methodologies, and processing techniques; developing new UASbased approaches for rapid topo-bathymetric surveying; and developing model-data integration frameworks to improve risk analysis and fusion data sources. 


\section{References}

Adams, S. M., and C. J. Friedland. 2011. "A Survey of Unmanned Aerial Vehicle (UAV) Usage for Imagery Collection in Disaster Research and Management.” In 9th International Workshop on Remote Sensing for Disaster Response, 2011. Palo Alto, CA. https://pdfs.semanticscholar.org/fd8e/960ca48e183452335743c273ea41c6930a75.pdf.

Anderson, K., and K. J. Gaston. 2013. "Lightweight Unmanned Aerial Vehicles Will Revolutionize Spatial Ecology." Frontiers in Ecology and the Environment 11(3): 138-146.

Association of Governmental Risk Pools (AGRiP). 2015. Use and Regulation of Drones by Local Government Entities \& Schools. http://www.agrip.org/assets/1/6/Drones/ssueAnalysisJuly2015.pdf.

Bakuła, K., A. Salach, D. Z. Wziątek, W. Ostrowski, K. Górski, and Z. Kurczyński. 2017. "Evaluation of the Accuracy of Lidar Data Acquired Using a UAS for Levee Monitoring: Preliminary Results." International Journal of Remote Sensing 38(8-10): 2921-2937.

Bandini, F., M. Butts, D. H. Olesen, J. Jakobsen, and P. Bauer-Gottwein. 2017. "Measuring Water Heights in Rivers and Lakes from Lightweight Unmanned Aerial Vehicles (UAVs)." In 11th Annual Danish Water Forum (DWF). Frederiksburg: University of Copenahgen.

Battisti C., G. Poeta, and G. Fanelli. 2016. "Classification Criteria for Disturbance Events." In An Introduction to Disturbance Ecology. Environmental Science and Engineering. Switzerland: Springer International Publishing.

Blaschke, T., G. J. Hay, M. Kelly, S. Lang, P. Hofmann, E. Addink, R. Q. Feitosa, R. van der Meer, H. van der Werff, F. van Coillie, and D. Tiede. 2014. "Geographic Object-Based Image Analysis-Towards a New Paradigm.” ISPRS Journal of Photogrammetry and Remote Sensing 87: 180-191.

Blom, J. D. 2010. Unmanned Aerial Systems: A Historical Perspective. (Occasional Paper 37). Fort Leavenworth, KS: Combat Studies Institute Press. http://usacac.army.mil/cac2/cgsc/carl/download/csipubs/OP37.pdf.

Chabot, D., and D. M. Bird. 2012. "Evaluation of an Off-The-Shelf Unmanned Aircraft System for Surveying Flocks of Geese." Waterbirds 35(1): 170-174.

Chabot, D., V. Carignan, and D. M. Bird. 2014. "Measuring Habitat Quality for Least Bitterns in a Created Wetland with Use of a Small Unmanned Aircraft." Wetlands 34(3): 527-533.

Chairman of the Joint Chiefs of Staff Notice. 2012. Joint Unmanned Aircraft Systems Minimum Training Standards. CJCSI 3255.01. https://standards.globalspec.com/std/1668628/cjcsi-3255-01-ce-01. 
Christie, K. S., S. L. Gilbert, C. L. Brown, M. Hatfield, and L. Hanson. 2016. "Unmanned Aircraft Systems in Wildlife Research: Current and Future Applications of a Transformative Technology." Frontiers in Ecology and the Environment 14(5): 241-251.

Code of Federal Regulations. 2016. Title 14 Chapter I Subchapter F Part 107. http://www.ecfr.gov/. Also: https://www.ecfr.gov/cgi-bin/textidx? SID=db38831f6d346d8da7ce6b137171c216\&mc=true\&node=pt14.2.107\&rgn=div5.

Cress, J., M. Hutt, J. Sloan, M. Bauer, M. Feller, and S. Goplen. 2015. U.S. Geological Survey Unmanned Aircraft Systems (UAS) Roadmap 2014. U.S. Geological Survey Open-File Report 2015-1032. http://dx.doi.org/10.3133/ofr20151032.

Delacourt, C., P. Allemand, M. Jaud, P. Grandjean, A. Deschamps, J. Ammann, V. Cuq, and S. Suanez. 2009. "DRELIO: An Unmanned Helicopter for Imaging Coastal Areas.” Journal of Coastal Research 1489-1493. https://www.jstor.org/stable/25738037.

Evans, L. J., T. H. Jones, K. Pang, S. Saimin, and B. Goossens. 2016. "Spatial Ecology of Estuarine Crocodile (Crocodylus porosus) Nesting in a Fragmented Landscape.” Sensors 16(9): 1527.

Ezequiel, C. A. F., M. Cua, N. C. Libatique, G. L. Tangonan, R. Alampay, R. T. Labuguen, C. M. Favila, J. L. E. Honrado, V. Canos, C. Devaney, and A. B. Loreto. 2014. "UAV Aerial Imaging Applications for Post-Disaster Assessment, Environmental Management and Infrastructure Development.” In Unmanned Aircraft Systems (ICUAS), 2014 International Conference on 274-283. IEEE.

Federal Aviation Administration. 2016. https://www.faa.gov/uas/faqs/.

Fernandes, M. R., F. C. Aguiar, J. M. N. Silva, M. T. Ferreira, and J. M. C. Pereira. 2014. "Optimal Attributes for the Object Based Detection of Giant Reed in Riparian Habitats: A Comparative Study between Airborne High Spatial Resolution and WorldView-2 Imagery." Int. J. Appl. Earth Obs. Geoinf. 32: 79-91. http://dx.doi.org/10.1016/i.jag.2014.03.026.

Flynn, K. F., and S. C. Chapra. 2014. "Remote Sensing of Submerged Aquatic Vegetation in a Shallow Non-Turbid River Using an Unmanned Aerial Vehicle." Remote Sensing 6(12): 12815-12836.

Fonstad, M. A., J. T. Dietrich, B. C. Courville, J. L. Jensen, and P. E. Carbonneau. 2013. "Topographic Structure from Motion: A New Development in Photogrammetric Measurement." Earth Surface Processes and Landforms 38(4): 421-430.

Frankenberger, J. R., C. Huang, and K. Nouwakpo. 2008. "Low-Altitude Digital Photogrammetry Technique to Assess Ephemeral Gully Erosion.” Geoscience and Remote Sensing Symposium, 2008. IGARSS 2008. IEEE International. https://ieeexplore.ieee.org/document/4779670/.

Getzin, S., R. S. Nuske, and K. Wiegand. 2014. "Using Unmanned Aerial Vehicles (UAV) to Quantify Spatial Gap Patterns in Forests." Remote Sensing 6(8): 6988-7004. 
Gong, J. 2014. "A Remote Sensing-Based Approach for Assessing and Visualizing PostSandy Damage and Resiliency Rebuilding Needs.” In Construction Research Congress 2014: Construction in a Global Network, 1259-1268. https://ascelibrary.org/doi/abs/10.1061/9780784413517.129.

Grenzdörffer, G. J. 2013. "UAS-Based Automatic Bird Count of a Common Gull Colony.” Int Arch Photogramm Remote Sens Spat Inf Sci XL-1 W 2: 169-174. https://www.int-arch-photogramm-remote-sens-spatial-inf-sci.net/XL-1W2/169/2013/isprsarchives-XL-1-W2-169-2013.pdf.

Higgins, J. K., 2016. Design, Testing and Evaluation of Robotic Mechanisms and Systems for Environmental Monitoring and Interaction. https://digitalcommons.unl.edu/mechengdiss/99/.

Hobbs, A., and S. Herwitz. 2006. Human Challenges in the Maintenance of Unmanned Aircraft Systems. Ten-month interim report prepared in accord with interagency agreement DTFA01-01- X-02045 between Federal Aviation Administration (FAA) Human Factors Research and 15 Engineering Division and National Aeronautics and Space Administration (NASA) Aeronautical Safety and Human Factors. https://humanfactors.arc.nasa.gov/publications/UAV_interimreport_Hobbs_Herwitz.pdf.

Impacts in the United States. 2009. Cambridge University Press. http://www.iooc.us/wpcontent/uploads/2010/09/Global-Climate-Change-Impacts-in-the-United-States.pdf.

Israel, M. 2011. “A UAV-Based Roe Deer Fawn Detection System.” International Archives of Photogrammetry and Remote Sensing 38: 1-5.

Jensen, J. R. 1996. Introductory Digital Image Processing: A Remote Sensing Perspective (No. Ed. 2). Prentice-Hall Inc. https://openlibrary.org/search?q=introductory+digital+image+processing $\% 3 \mathrm{~A}+\mathrm{a}+$ +remote+sensi ng+perspective\&mode $=$ everything.

Jones IV, G. P., L. G. Pearlstine, and H. F. Percival. 2006. "An Assessment of Small Unmanned Aerial Vehicles for Wildlife Research." Wildlife Society Bulletin 34(3): 750-758.

Kahvecioglu, S., and H. Oktal. 2016. "Historical Development of UAV Technologies in the World: The Case of Turkey." In Sustainable Aviation, 323-331. Springer International Publishing.

Karaağaç, C., A. G. Pakfiliz, F. Quagliotti, and N. Alemdaroglu. 2015. "UAV Logistics for Life-Cycle Management." In Handbook of Unmanned Aerial Vehicles, 26012635). Netherlands: Springer.

Karl, T. R., J. M. Melillo, and T. C. Peterson. 2009. Global Climate Change Impacts in the United States. Cambridge: Cambridge University Press.

Kerr, J. T., and M. Ostrovsky. 2003. "From Space to Species: Ecological Applications for Remote Sensing." Trends in Ecology \& Evolution 18(6): 299-305.

Klemas, V. V. 2015. "Coastal and Environmental Remote Sensing from Unmanned Aerial Vehicles: An Overview.” Journal of Coastal Research 31(5): 1260-1267. 
Koh, L. P., and S. A. Wich. 2012. "Dawn of Drone Ecology: Low-Cost Autonomous Aerial Vehicles for Conservation.” Tropical Conservation Science 5(2): 121-132.

Kopardekar, P., J. Rios, T. Prevot, M. Johnson, J. Jung, and J. Robinson. 2016. "Unmanned Aircraft System Traffic Management (UTM) Concept of Operations." In 16th AIAA Aviation Technology, Integration, and Operations Conference, AIAA Aviation. https://www.utm.arc.nasa.gov/docs/Kopardekar_2016-3292_ATI0.pdf.

Laliberte, A. S., and A. Rango. 2009. "Texture and Scale in Object-Based Analysis of Subdecimeter Resolution Unmanned Aerial Vehicle (UAV) Imagery.” IEEE Transactions on Geoscience and Remote Sensing 47(3): 761-770.

Lillesand, T. M., R. W. Kiefer, and J. Chipman. 2014. Remote Sensing and Image Interpretation. New York: John Wiley and Sons.

Linchant, J., J. Lisein, J. Semeki, P. Lejeune, and V. Vermeulen. 2015. “Are Unmanned Aircraft Systems (UASs) the Future of Wildlife Monitoring? A Review of Accomplishments and Challenges." Mammal Review 45(4): 239-252.

Lisein, J., J. Linchant, P. Lejeune, P. Bouché, and C. Vermeulen. 2013. “Aerial Surveys Using an Unmanned Aerial System (UAS): Comparison of Different Methods for Estimating the Surface Area of Sampling Strips.” Tropical Conservation Science 6(4): 506-520.

Loarie S. R., L. N. Joppa, and S. L. Pimm. 2007. "Satellites Miss Environmental Priorities." Trends in Ecology and Evolution 22: 630.

Longmore, S. N., R. P. Collins, S. Pfeifer, S. E. Fox, M. Mulero-Pazmany, F. Bezombes, A. Goodwind, M. Ovelar, J. H. Knapen, and S. A. Wich. 2017. Adapting Astronomical Source Detection Software to Help Detect Animals in Thermal Images Obtained by Unmanned Aerial Systems. arXiv preprint arXiv:1701.01611. Also: https://www.tandfonline.com/doi/full/10.1080/01431161.2017.1280639.

Lucintel. 2011. Growth Opportunity in Global UAV Market. Las Colinas, USA. http://www.lucintel.com/lucintelbrief/uavmarketopportunity.pdf.

Ma, L., M. Li, L. Tong, Y. Wang, and L. Cheng. 2013. "Using Unmanned Aerial Vehicle for Remote Sensing Application.” In Geoinformatics, 2013 21st International Conference, 1-5. IEEE.

Merino, L., F. Caballero, J. R. Martínez-de-Dios, I. Maza, and A. Ollero. 2012. “An Unmanned Aircraft System for Automatic Forest Fire Monitoring and Measurement." Journal of Intelligent \& Robotic Systems 65(1): 533-548.

Michez, A., H. Piégay, L. Jonathan, H. Claessens, and P. Lejeune. 2016. "Mapping of Riparian Invasive Species with Supervised Classification of Unmanned Aerial System (UAS) Imagery." International Journal of Applied Earth Observation and Geoinformation 44: 88-94.

Müllerová, J., J. Pergl, and P. Pysek. 2013. "Remote Sensing as a Tool for Monitoring Plant Invasions: Testing the Effects of Data Resolution and Image Classification Approach on the Detection of a Model Plant Species Heracleum mantegazzianum (Giant Hogweed).” Int. J. Appl. Earth Obs. Geoinf. (25): 55-65. http://dx.doi.org/10.1016/j.jag.2013.03.004. 
Müllerová, J., P. Pysek, V. Jarosík, and J. Pergl. 2005. “Aerial Photographs as a Tool for Assessing the Regional Dynamics of the Invasive Plant Species Heracleum mantegazzianum." J. Appl. Ecol. 42: 1042-1053. https://besjournals.onlinelibrary.wiley.com/doi/epdf/10.1111/i.1365-2664.2005.01092.x.

Paneque-Gálvez, J., M. K. McCall, B. M. Napoletano, S. A. Wich, and L. P. Koh. 2014. "Small Drones for Community-Based Forest Monitoring: An Assessment of Their Feasibility and Potential in Tropical Areas." Forests 5(6): 1481-1507.

Papakonstantinou, A., K. Topouzelis, and G. Pavlogeorgatos. 2016. "Coastline Zones Identification and 3D Coastal Mapping Using UAV Spatial Data." ISPRS International Journal of Geo-Information 5(6): 75.

Ramsey, J. W. 2005. "UAVs: Out of Uniform.” Aviation Today. http://www.aviationtoday.com/2004/03/01/uavs-out-of-uniform/.

Rathinam, S., Z. Kim, and R. Sengupta. 2008. "Vision-Based Following of Locally Linear Structures Using an Unmanned Aerial Vehicle." Journal of Infrastructure Systems 14(1) 52-63.

Sardá-Palomera, F., G. Bota, C. Vinolo, O. Pallares, V. Sazatornil, L. Brotons, S. Gomáriz, and F. Sardá. 2012. "Fine-Scale Bird Monitoring from Light Unmanned Aircraft Systems.” Ibis 154(1): 177-183.

Science Encyclopedia. 2017. http://science.jrank.org/.

Seymour, A. C., J. Dale, M. Hammill, P. N. Halpin, and D. W. Johnston. 2017. "Automated Detection and Enumeration of Marine Wildlife Using Unmanned Aircraft Systems (UAS) and Thermal Imagery.” Scientific Reports 7. https://www.ncbi.nlm.nih.gov/pmc/articles/PMC5364474/.

Sheng, H., H. Chao, C. Coopmans, J. Han, M. McKee, and Y. Chen. 2010. "Low-Cost UAV-Based Thermal Infrared Remote Sensing: Platform, Calibration and Applications." In Mechatronics and Embedded Systems and Applications (MESA), 2010 IEEE/ASME International Conference, 38-43. IEEE.

Siebert, S., and J. Teizer. 2014. "Mobile 3D Mapping for Surveying Earthwork Projects Using an Unmanned Aerial Vehicle (UAV) System.” Automation in Construction 41: $1-14$.

Soleimani, B., M.-H. Z. Ashtiani, B. H. Soleimani, and H. Moradi. 2010. “A Disaster Invariant Feature for Localization.” International Conference on Intelligent Robots and Systems (IROS), 2010 IEEE/RSJ.

Tamminga, A. D., B. C. Eaton, and C. H. Hugenholtz. 2015. "UAS-Based Remote Sensing of Fluvial Change Following an Extreme Flood Event.” Earth Surface Processes and Landforms 40(11): 1464-1476.

Tang, L., and G. Shao. 2015. "Drone Remote Sensing for Forestry Research and Practices.” Journal of Forestry Research 26(4): 791-797.

U.S. Army Corps of Engineers (USACE). 2016a. Acquisition and Operation of Unmanned Aircraft Systems (UAS) Technology. EC 1110-1-106. Washington, DC: U.S. Army Corps of Engineers. 
USACE. 2016b. Jacksonville District Unmanned Aerial System Section - Capabilities and Specifications Fact Sheet. Jacksonville District, U.S. Army Corps of Engineers. http://bit.ly/JaxStrong_UAV.

U.S. Geological Survey (USGS). 2017. National UAS Project Office: Research Missions. https://uas.usgs.gov/mission.shtml.

van Gemert, J. C., C. R. Verschoor, P. Mettes, K. Epema, L. P. Koh, and S. Wich. 2014. "Nature Conservation Drones for Automatic Localization and Counting of Animals." In Workshop at the European Conference on Computer Vision, 255270. Springer International Publishing.

Van Iersel, W. K., M. W. Straatsma, E. A. Addink, and H. Middelkoop. 2016. "Monitoring Phenology of Floodplain Grassland and Herbaceous Vegetation with UAV Imagery.” In XXIII ISPRS Congress, Commission VII, 12-19 July 2016, Prague, Czech Republic (Vol. 41, 569-571). International Society for Photogrammetry and Remote Sensing.

Ventura, D., M. Bruno, G. J. Lasinio, A. Belluscio, and G. Ardizzone. 2016. “A Low-Cost Drone Based Application for Identifying and Mapping of Coastal Fish Nursery Grounds." Estuarine, Coastal and Shelf Science 171: 85-98.

Vericat, D., J. Brasington, J. Wheaton, and M. Cowie. 2009. "Accuracy Assessment of Aerial Photographs Acquired Using Lighter-than-Air Blimps: Low-Cost Tools for Mapping River Corridors.” River Research and Applications 25(8): 985-1000.

Vincent J. B., L. K. Werden, and M. A. Ditmer. 2015. "Barriers to adding UAVs to the Ecologist's Toolbox." Frontiers in Ecology and the Environment 13: 74-75.

Weissensteiner, M. H., J. W. Poelstra, and J. B. Wolf. 2015. "Low-Budget Ready-to-Fly Unmanned Aerial Vehicles: An Effective Tool for Evaluating the Nesting Status of Canopy-Breeding Bird Species.” Journal of Avian Biology 46(4): 425-430.

Whitehead, K., and C. H. Hugenholtz. 2014. "Remote Sensing of the Environment with Small Unmanned Aircraft Systems (UASs), Part 1: A Review of Progress and Challenges 1." Journal of Unmanned Vehicle Systems 2(3): 69-85.

Wozencraft, J. M. 2010. "Requirements for the Coastal Zone Mapping and Imaging Lidar (CZMIL).” In SPIE Defense, Security, and Sensing. Orlando (FL): International Society for Optics and Photonics, 76950Q-76950Q.

Wulder, M. A., R. J. Hall, N. C. Coops, and S. E. Franklin.. 2004. "High Spatial Resolution Remotely Sensed Data for Ecosystem Characterization.” BioScience 54(6): 511521.

Zarco-Tejada, P. J., R. Diaz-Varela, V. Angileri, and P. Loudjani. 2014. "Tree Height Quantification Using Very High Resolution Imagery Acquired from an Unmanned Aerial Vehicle (UAV) and Automatic 3D Photo-Reconstruction Methods.” European Journal of Agronomy 55: 89-99. 


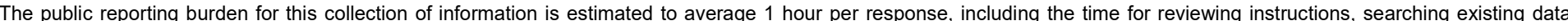

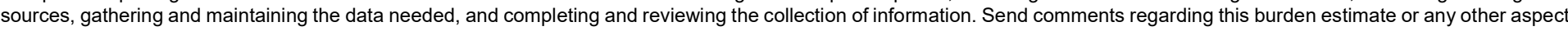

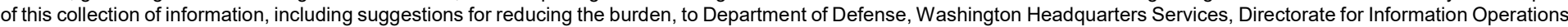

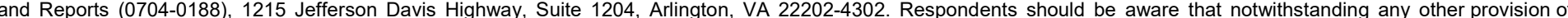
law, no person shall be subject to any penalty for failing to comply with a collection of information if it does not display a currently valid OMB control number.

PLEASE DO NOT RETURN YOUR FORM TO THE ABOVE ADDRESS.

\begin{tabular}{l|l|l}
\hline $\begin{array}{l}\text { 1. REPORT DATE } \\
\text { June } 2018\end{array}$ & $\begin{array}{l}\text { 2. REPORT TYPE } \\
\text { Final Report }\end{array}$ & 3. DATES COVERED (From - To)
\end{tabular}

\section{TITLE AND SUBTITLE}

Final Report

Unmanned Aircraft Systems to Support Environmental Applications within USACE Civil

Works

5a. CONTRACT NUMBER

5b. GRANT NUMBER

5c. PROGRAM ELEMENT NUMBER

6. $\operatorname{AUTHOR(S)}$

Glenn M. Suir, Molly Reif, Shea Hammond, Sam Jackson,

and Katherine Brodie

5d. PROJECT NUMBER

468426

468431

5e. TASK NUMBER

5f. WORK UNIT NUMBER

7. PERFORMING ORGANIZATION NAME(S) AND ADDRESS(ES) (see reverse)

\section{PERFORMING ORGANIZATION REPORT NUMBER}

ERDC SR-18-3

10. SPONSOR/MONITOR'S ACRONYM(S)

USACE

U.S. Army Corps of Engineers

Washington, DC 20314-1000

11. SPONSOR/MONITOR'S REPORT NUMBER(S)

\section{DISTRIBUTION/AVAILABILITY STATEMENT}

Approved for public release; distribution is unlimited.

\section{SUPPLEMENTARY NOTES}

\section{ABSTRACT}

The combination of static infrastructure with dynamic and diverse landscapes creates management challenges for navigation, storm damage reduction, and ecosystem health that are exacerbated during natural disasters. To accomplish the U.S. Army Corps of Engineers (USACE) flood risk management (FRM) mission, accurate and updated identification of environmental, physical, and infrastructure features is required. The USACE has identified a number of Research and Development (R\&D) opportunities to help reduce disaster risks, including cost-efficient technology, such as Unmanned Aircraft System (UAS) technology for accurate, detailed, and timely twodimensional and three-dimensional monitoring of coastal and riverine landscapes. To that end, the USACE Flood and Coastal Systems R\&D Program has initiated an effort focused on identifying and developing defendable and consistent UAS-based methodologies and data products to help address FRM goals. Specifically, this report focuses on identifying the role of UAS technology to support environmental missions and applications related to FRM. While it does not address operational classification, guidance, and policies, which have been established and published, the report does include a technical review with district feedback of USACE-related environmental needs, and it assesses the role of UAS-based data product research and development.

\section{SUBJECT TERMS}

Coasts, Data collection platforms, Drone aircraft, Hydraulic structures, Micro air vehicles, Rivers

\section{SECURITY CLASSIFICATION OF:}

\begin{tabular}{|l|c|l|l|} 
a. REPORT & b. ABSTRACT & c. THIS PAGE & \multirow{2}{*}{ ABSTRACT } \\
Unclassified & Unclassified & Unclassified & SAR \\
& & &
\end{tabular}

18. NUMBER OF 19a. NAME OF RESPONSIBLE PERSON \begin{tabular}{l|l} 
PAGES & Molly Reif
\end{tabular}

$43 \quad$ 19b. TELEPHONE NUMBER (Include area code) $228-252-1134$ 
7. PERFORMING ORGANIZATION NAME(S) AND ADDRESS(ES) (continued)

Environmental Laboratory

U.S. Army Engineer Research and Development Center

Louisiana State University - Military Sciences Building

Baton Rouge, LA 70803

Environmental Laboratory

U.S. Army Engineer Research and Development Center

Joint Airborne Lidar Bathymetry Technical Center of Expertise

Kiln, MS 39556

Environmental Laboratory

U.S. Army Engineer Research and Development Center

Vicksburg, MS 39180-6199

Coastal and Hydraulics Laboratory

U.S. Army Engineer Research and Development Center

Duck, NC 27949 